\title{
Somatodendritic Kv7/KCNQ/M Channels Control Interspike Interval in Hippocampal Interneurons
}

\author{
J. Josh Lawrence, ${ }^{1 *}$ Fernanda Saraga, ${ }^{2,3,4 *}$ Joseph F. Churchill, ${ }^{1}$ Jeffrey M. Statland, ${ }^{1}$ Katherine E. Travis, ${ }^{1}$ \\ Frances K. Skinner, $, 3,3,4,5$ and Chris J. McBain ${ }^{1}$ \\ ${ }^{1}$ Laboratory of Cellular and Synaptic Neurophysiology, National Institute of Child Health and Human Development, National Institutes of Health, Bethesda, \\ Maryland 20892, ${ }^{2}$ Toronto Western Research Institute, University Health Network, ${ }^{3}$ Department of Physiology, ${ }^{4}$ Department of Medicine (Neurology), and \\ Institute of Biomaterials and Biomedical Engineering, University of Toronto, Toronto, Ontario, Canada M5T 2S8
}

The M-current $\left(I_{\mathrm{M}}\right)$, comprised of Kv7 channels, is a voltage-activated $\mathrm{K}^{+}$conductance that plays a key role in the control of cell excitability. In hippocampal principal cells, $I_{\mathrm{M}}$ controls action potential (AP) accommodation and contributes to the medium-duration afterhyperpolarization, but the role of $I_{\mathrm{M}}$ in control of interneuron excitability remains unclear. Here, we investigated $I_{\mathrm{M}}$ in hippocampal stratum oriens (SO) interneurons, both from wild-type and transgenic mice in which green fluorescent protein (GFP) was expressed in somatostatin-containing interneurons. Somatodendritic expression of Kv7.2 or Kv7.3 subunits was colocalized in a subset of GFP+SO interneurons, corresponding to oriens-lacunosum moleculare (0-LM) cells. Under voltage clamp (VC) conditions at $-30 \mathrm{mV}$, the $\mathrm{Kv} 7$ channel antagonists linopirdine/XE-991 abolished the $I_{\mathrm{M}}$ amplitude present during relaxation from -30 to $-50 \mathrm{mV}$ and reduced the holding current $\left(I_{\text {hold }}\right)$. In addition, $0.5 \mathrm{~mm}$ tetraethylammonium reduced $I_{\mathrm{M}}$, suggesting that $I_{\mathrm{M}}$ was composed of Kv7.2-containing channels. In contrast, the Kv7 channel opener retigabine increased $I_{\mathrm{M}}$ amplitude and $I_{\text {hold }}$. When strongly depolarized in VC, the linopirdine-sensitive outward current activated rapidly and comprised up to $20 \%$ of the total current. In current-clamp recordings from GFP + SO cells, linopirdine induced depolarization and increased AP frequency, whereas retigabine induced hyperpolarization and arrested firing. In multicompartment 0-LM interneuron models that incorporated $I_{\mathrm{M}}$, somatodendritic placement of Kv7 channels best reproduced experimentally measured $I_{\mathrm{M}}$. The models suggest that Kv3- and Kv7-mediated channels both rapidly activate during single APs; however, Kv3 channels control rapid repolarization of the AP, whereas Kv7 channels primarily control the interspike interval.

Key words: antiepileptic; action potential; hippocampus; interneuron; M-current; neuromodulation; potassium channel

\section{Introduction}

The M-current $\left(I_{\mathrm{M}}\right)$ is a $\mathrm{K}^{+}$conductance known to operate at subthreshold voltages and is a common target of neuromodulation throughout the CNS (Jentsch, 2000; Cooper and Jan, 2003). In CA1 pyramidal cells, $I_{\mathrm{M}}$ is inhibited by muscarinic acetylcholine receptor (mAChR) activation (Halliwell and Adams, 1982), controls action potential (AP) frequency (Gu et al., 2005), and generates a medium afterhyperpolarization (mAHP) after single or multiple APs (Gu et al., 2005) that prevents the development of a postspike afterdepolarization (Yue and Yaari, 2004). In these

Received March 17, 2006; revised 0ct. 12, 2006; accepted 0ct. 14, 2006.

This work was supported by National Institute of Child Health and Human Development intramural funding to C.J.M., Science and Engineering Research Canada [Natural Sciences and Engineering Research Council of Canada (NSERC)] funding to F.K.S., and an NSERC Postgraduate and Ontario Graduate Scholarship to F.S. J.F.C. and J.M.S. are Howard Hughes Medical Institute-National Institutes of Health Research Scholars. We thank Dr. Zachary Grinspan for preliminary experiments and analysis code, Brian Jeffries for biocytin immunocytochemistry and Neurolucida reconstructions, Dr. Melanie Tallent for immunochemistry protocols, Xioqing Yuan for expert technical assistance with Kv3.1/Kv3.2 transfections, Dr. Bernardo Rudy for Kv3.1/Kv3.2 plasmids, Dr. Michael Rogawski for the gift of retigabine, and Dr. Dax Hoffman for critically reading a previous version of this manuscript.

*J.J.L. and F.S. contributed equally to this work.

Correspondence should be addressed to either of the following: Josh Lawrence at the above address, E-mail: lawrenjo@mail.nih.gov; or Fernanda Saraga, Department of Zoology, Room 303, University of Toronto, 25 Harbord Street, Toronto, Canada M5S 3G5, E-mail: fernanda.saraga@utoronto.ca.

DOI:10.1523/JNEUROSCI.3521-06.2006

Copyright $\odot 2006$ Society for Neuroscience $\quad 0270-6474 / 06 / 2612325-14 \$ 15.00 / 0$ cells, $I_{\mathrm{M}}$ is probably composed of Kv7.2 and Kv7.3 channel subunits (Wang et al., 1998; Shah et al., 2002), the expression of which is critical in controlling cell and network excitability (Peters et al., 2005).

Hippocampal interneurons are also highly sensitive to neuromodulation (Parra et al., 1998), which may be important in promoting coherent oscillations and synchronization in the hippocampus (Toth et al., 1997; Buzsaki, 2002; Cobb and Davies, 2005; Lawrence et al., 2006b). Although interneurons are strongly activated by acetylcholine (McQuiston and Madison, 1999; Lawrence et al., 2006a) and possess numerous $\mathrm{K}^{+}$conductances (Zhang and McBain, 1995a,b; Martina et al., 1998, 2000; Lien et al., 2002; Lien and Jonas, 2003), the question of whether interneurons possess $I_{M}$ has received little attention. Recently, we demonstrated that oriens-lacunosum moleculare (O-LM) cells generate a large mAChR-dependent afterdepolarization that is partially dependent on $I_{M}$ inhibition (Lawrence et al., 2006a), but the nature of how $I_{\mathrm{M}}$ itself impacts excitability in stratum oriens (SO) interneurons has not yet been explored in detail. Moreover, the cellular localization of Kv7 channels in neurons has recently become a point of interest. Although early immunocytochemical evidence indicated that Kv7 subunits were localized somatodendritically on hippocampal pyramidal cells (Cooper et al., 2000; Shah et al., 2002) and interneurons (Cooper et al., 2001), an 
additional population of Kv7 channels has been more recognized recently on the axon initial segment and nodes of Ranvier of CNS neurons (Devaux et al., 2004; Chung et al., 2006; Pan et al., 2006). Kv7 channel antagonists modulate axonal excitability (Devaux et al., 2004), raising uncertainty about whether axonal or dendritic Kv7 channels mediate $I_{\mathrm{M}}$-dependent changes in cellular excitability originally described in hippocampal pyramidal neurons (Yue and Yaari, 2004; Gu et al., 2005) and interneurons (Lawrence et al., 2006a).

In this study, we identified Kv7 channels in CA1 SO interneurons through both immunocytochemical and electrophysiological means. We built realistic multicompartment interneuron models and explored how the cellular localization of Kv7 channels influenced the somatic detection of $I_{\mathrm{M}}$ measured experimentally. We found that both experimentally measured $I_{\mathrm{M}}$ and its influence on cellular excitability could be best reproduced by somatodendritic placement of Kv7 channels. Using our model, we found that $I_{\mathrm{M}}$ is strongly recruited by APs and is a major dendritic conductance controlling the interspike interval (ISI) in hippocampal interneurons.

\section{Materials and Methods}

Immunocytochemistry. All experiments were conducted in accordance with animal protocols approved by the National Institutes of Health. To permit quantification of Kv7.2 (KCNQ2) and Kv7.3 (KCNQ3) subunits in anatomically identified interneuronal populations, a mouse strain was chosen in which green fluorescent protein (GFP) is expressed in a population of inhibitory neurons [the GFP-expressing inhibitory neurons (GIN) line of transgenic mice (Oliva et al., 2000)]. In the CA1 hippocampus, GIN mice label a population of somatostatin-positive (SOM+) interneurons that project axonally to stratum lacunosum moleculare (SLM) (Oliva et al., 2000). GFP+ SO interneurons are solely comprised of the well characterized O-LM cells, whereas GFP+ cells in stratum radiatum (SR) form a relatively newly discovered population of SOM+ neurons that also project to SLM. Male mice of both GIN and wild-type (B6/C57J; Charles River Laboratories, Wilmington, MA) animals, 3-6 months of age, were perfused using an ice-cold $0.1 \mathrm{M}$ phosphate buffer solution containing $4 \%$ paraformaldehyde and $15 \%$ picric acid, adjusted to $\mathrm{pH} 7.4$ with $\mathrm{NaOH}$. Briefly, the brains were fixed overnight, cryoprotected in $30 \%$ sucrose for several days, sliced to $30 \mu \mathrm{m}$ thickness using a freezing microtome, and kept at $4^{\circ} \mathrm{C}$ for up to 3 weeks until used. Freefloating sections were incubated with primary antibodies for $12-48 \mathrm{~h}$ in a $0.1 \mathrm{M}$ PBS containing $0.1 \%$ Triton X-100 and $4 \%$ BSA (Sigma-Aldrich, St. Louis, MO). Rabbit-KCNQ2 (1:3000) and rabbit-KCNQ3 (1:2000) primary antibodies were used (Chemicon, Temecula, CA), comparable with that originally described by Yus-Najera et al. (2003). In slices containing GFP + interneurons, the goat anti-rabbit secondary antibody Alexa Fluoro 633 (1:1000 dilution; Invitrogen, Carlsbad, CA) was chosen to ensure sufficient separation from the GFP wavelength. After incubation of the secondary antibody for $60 \mathrm{~min}$ at room temperature, processed slices were mounted onto Superfrost Plus slides (Fisher Scientific, Pittsburgh, PA), allowed to dry, immersed in Mowiol (Calbiochem, La Jolla, CA), coverslipped, and dried overnight. Confocal microscopy was performed using either Leica (Exton, PA) TCS or Zeiss (Thornwood, NY) LSM 510 2-Photon Meta confocal microscopes. For the laminar quantification of Kv7.2 + or Kv7.3 + cells within GFP+ interneuronal populations, cell counts, detected by eye, were based on a total of four brains, 20 slices per brain, and 40 images (both hemispheres) of CA1 hippocampus. Images of CA1 hippocampus were loaded into the confocal module of Neurolucida (Autoneuron v.6.0; MicroBrightField, Williston, VT) and quantified in contour mode. GFP/488 and Kv7/633 channels were viewed independently and together to ensure unambiguous colocalization of Kv7 subunits in GFP+ populations. As controls, sections omitting the primary antibody, or omitting both primary and secondary antibodies, were processed in parallel and imaged at the same confocal settings (i.e., gain and pinhole size).

Electrophysiology. Transverse hippocampal slices $(300 \mu \mathrm{m})$ were cut from 14- to 21-d-old mice from 129J1(50\%) $\times$ CF1(50\%), C57/B6, or $\mathrm{FVB} / \mathrm{N}$ backgrounds. The dissection solution consisted of the following (in mM): $130 \mathrm{NaCl}, 3.5 \mathrm{KCl}, 1.25 \mathrm{NaH}_{2} \mathrm{PO}_{4}, 25 \mathrm{NaHCO}_{3}, 10$ glucose, 7 $\mathrm{MgCl}_{2}, 0.5 \mathrm{CaCl}_{2}$, saturated with $95 \% \mathrm{O}_{2} / 5 \% \mathrm{CO}_{2}, \mathrm{pH}$ 7.4. In more recent experiments, a partial sucrose cutting ringer was used, consisting of the following (in $\mathrm{mm}$ ): $80 \mathrm{NaCl}, 24 \mathrm{NaHCO}_{3}, 25$ glucose, 75 sucrose, $2.5 \mathrm{KCl}, 1.25 \mathrm{NaH}_{2} \mathrm{PO}_{4}, 4 \mathrm{MgCl}_{2}, 0.5 \mathrm{CaCl}_{2}, 3 \mathrm{Na}$-pyruvate, 1 ascorbate, saturated with $95 \% \mathrm{O}_{2} / 5 \% \mathrm{CO}_{2}, \mathrm{pH}$ 7.4. Experiments were conducted using an upright Zeiss microscope and submerged slice chamber (Infrapatch; Luigs and Neumann, Ratingen, Germany). The speed of solution exchange was $\sim 1 \mathrm{~min}$, as estimated by a single exponential fit to the mean change in $I_{\text {hold }}$ at $-30 \mathrm{mV}$ by $10 \mu \mathrm{m}$ linopirdine (see Fig. $2 \mathrm{I}$ ). Loose patch and whole-cell patch-clamp recordings were made from visually identified interneurons on the SO/alveus border of the CA1 using an Axoclamp 200B or Multiclamp 700A amplifier (Molecular Devices, Union City, $\mathrm{CA}$ ), filtered at $3 \mathrm{kHz}$ (Bessel filter; Frequency Devices, Haverhill, MA), and digitized at $10-40 \mathrm{kHz}$ (Digidata 1320A and pClamp Software; Molecular Devices). Loose-patch recordings were chosen over tight seal recordings for their noninvasiveness and excellent signal-to-noise ratio (Nunemaker et al., 2003; Pouille and Scanziani, 2004). A 3-5 M 2 electrode was placed on the soma, and negative suction was applied to the pipette until a low resistance seal of $\sim 7-20 \mathrm{M} \Omega$ was achieved. Action currents were recorded in voltage clamp (VC) mode with no voltage applied $(V=0)$. Stability of the loose-patch recording was monitored via a $-1 \mathrm{mV}, 100 \mathrm{~ms}$ duration step at 30 s intervals. Unless otherwise stated, for whole-cell recordings, the extracellular solution (ECS) contained the following (in mM): $125 \mathrm{NaCl}, 2.5 \mathrm{KCl}, 2 \mathrm{CaCl}_{2}, 1 \mathrm{MgCl}_{2}, 1.25 \mathrm{NaH}_{2} \mathrm{PO}_{4}$, and 20 glucose. DL-APV $(100 \mu \mathrm{M})$, DNQX $(25 \mu \mathrm{M})$, and gabazine $(5 \mu \mathrm{M})$ were added to the ECS to block NMDA, AMPA, kainate, and $\mathrm{GABA}_{\mathrm{A}}$ receptors, respectively. Except in loose-patch and current-clamp (CC) recordings (see Fig. 7), tetrodotoxin ( $1 \mu \mathrm{M})$ was added and $\mathrm{CsCl}(5 \mathrm{mM})$ was replaced with equimolar $\mathrm{NaCl}$ in $\mathrm{VC}$ experiments to block $\mathrm{Na}^{+}$ channels and the hyperpolarization-activated current $I_{\mathrm{h}}$, respectively. For $\mathrm{VC}$ recordings in which strong depolarizing voltage steps were introduced, $\mathrm{CaCl}_{2}$ was lowered to $0-0.5 \mathrm{~mm}$ and $\mathrm{MgCl}_{2}$ elevated to $2-4 \mathrm{~mm}$ to reduce the activation of a slow $\mathrm{Ca}^{2+}$-activated $\mathrm{K}^{+}$conductance (Lawrence et al., 2006a). In some experiments, $50 \mu \mathrm{M} \mathrm{CdCl}{ }_{2}$ or $2 \mathrm{~mm}$ EGTA was added to further reduce the influence of $I_{\mathrm{AHP}}$. Recording pipettes were filled with the following (in $\mathrm{mM}$ ): $135 \mathrm{~K}$-gluconate, 10 HEPES, 0.1 EGTA, $2 \mathrm{Na}_{2} \mathrm{ATP}, 0.3 \mathrm{Na}_{2} \mathrm{GTP}, 20 \mathrm{KCl}$, pH 7.3. In more recent experiments, to take additional precautions against the possibility of $I_{\mathrm{M}}$ rundown (Suh and Hille, 2002), an intracellular solution was used containing the following (in $\mathrm{mm}$ ): $110 \mathrm{~K}$-gluconate, $10 \mathrm{HEPES}, 0.1 \mathrm{EGTA}, 4$ Mg-ATP, $0.3 \mathrm{Na}_{2}$ GTP, $10 \mathrm{Na}$-phosphocreatine, pH 7.2. Biocytin (0.2\%) was added for post hoc morphological processing of each recorded cell. Linopirdine and XE-991 (XE) were purchased from Tocris Cookson (Ellisville, MO); all other drugs were purchased from Sigma-Aldrich. Voltage measurements were not corrected for a calculated liquid junction potential of $-13.8 \mathrm{mV}$ but were accounted for in multicompartment models.

Electrophysiological analysis. Current-clamp analysis and leak subtraction was performed off-line using software written in Axograph 4.7 (Molecular Devices) by the authors. For the analysis of loose-patch recordings, spontaneous action currents were detected with a sliding template (derived from raw traces) using a detection threshold of three times the SD of the noise (Clements and Bekkers, 1997). For current-clamp analysis, APs were detected using a detection threshold of $5 \mathrm{~V} / \mathrm{s}$. For leak subtraction, a $-5 \mathrm{mV}$ seal test from $-60 \mathrm{mV}$ preceded each depolarizing stimulus. The steady-state current, derived from the single exponential fit to the average of 18-24 seal tests, was scaled to the voltage waveforms and subtracted from the average current trace. Outward currents generated by depolarizing voltage steps were the average of three separate trials. Traces obtained in control conditions and in the presence of $I_{\mathrm{M}}$ antagonists were both leak subtracted before obtaining XE-991 or linopirdine-sensitive components via digital subtraction.

For outward current traces measured in control and in the presence of $I_{\mathrm{M}}$ antagonists, deactivation was sufficiently described by three exponentials (see Fig. 6A), as judged by a more than twofold reduction in $\chi^{2}$ compared with a two exponential fit (Origin; Microcal, Northampton, 
MA). To overcome the poor signal-to-noise ratio in the XE-991 or linopirdine-subtracted traces, fitted exponentials curves obtained in control and drug condition were subtracted from each other. This yielded a curve that described the XE-991 or linopirdine-sensitive component well. Data are presented as means \pm SEM.

Transfection of human embryonic kidney 293 cells with Kv3.1/Kv3.2 plasmids. Human embryonic kidney 293 (HEK293) cells were cultured in DMEM $+10 \%$ FBS (Invitrogen). Transfections were performed using FuGENE6 Transfection Reagent (Roche Applied Science), according to the specifications of the manufacturer. cDNA clones expressing Kv3.1b or Kv3.2a were cotransfected with pIRES2-EGFP (Clontech, Cambridge, UK) at a ratio of $4: 1$. A total amount of $0.5 \mu \mathrm{g}$ of DNA was used to transfect $5 \mathrm{e}^{4}$ HEK293 in $1 \mathrm{ml}$ of suspension. After transfection, cells were plated on poly-D-lysine-coated $18 \mathrm{~mm}$ glass coverslips in 12-well plates. Outward currents were generated from isolated GFP + HEK293 cells 24-48 h after transfection. Data acquisition was made on two channels. On one channel, recording stability was monitored via the peaks of the capacitance transients; on the second channel, leak subtraction was performed with an on-line $\mathrm{P} / 4$ protocol using pClamp software.

Neurolucida reconstructions. In a subset of electrophysiological recordings, slices were fixed in $4 \%$ paraformaldehyde $(>24 \mathrm{~h}$ ) in $0.1 \mathrm{M}$ phosphate buffer. Slices were immersed in PBS and resectioned into $70 \mu \mathrm{m}$ sections on a freezing microtome. Biocytin staining was revealed using an avidin-biotin-peroxidase reaction (ABC Standard Kit; Vector Laboratories, Burlingame, CA). Slices were mounted on gelatin-coated glass slides, dehydrated, and coverslipped with Permount. Digital reconstruction of interneuron morphologies was performed with a Zeiss brightfield light microscope driven by Neurolucida software (MicroBrightField, Colchester, VT).

Multicompartment modeling of O-LM interneurons. Vector coordinate files of two O-LM cells (see Fig. 4, cells 1 and 2) were imported from Neurolucida to the shareware program cvapp (www.compneuro.org/ $\mathrm{CDROM} / \mathrm{docs} / \mathrm{cvapp} . \mathrm{html}$ ), which enabled the user to test electrical connectivity between soma and all processes. The reconstructions were then imported into NEURON (http://www.neuron.yale.edu).

The passive properties of a cell included the membrane capacitance, $C$, the axial resistivity, $R_{\mathrm{a}}$, the leak channel conductance, $\bar{g}_{\mathrm{L}}$, and the reversal potential of the leak channel, $E_{\mathrm{L}}$. For the multicompartment models here, an additional potassium leak channel was incorporated with conductance, $\bar{g}_{\mathrm{KL}}$, and reversal potential, $E_{\mathrm{K}}$. Passive properties $\left(R_{\mathrm{a}}, \bar{g}_{\mathrm{L}}, E_{\mathrm{L}}\right.$, and $\bar{g}_{\mathrm{KL}}$ ) were optimized uniformly throughout the somatic, dendritic, and axonal tree of the full morphology models to match experimentally measured current traces using a voltage step protocol from -60 to $-65 \mathrm{mV}$ for each particular cell (see Fig. $8 F$ ). The membrane capacitance, $C$, was fixed at $0.9 \mu \mathrm{F} / \mathrm{cm}^{2}$ (Gentet et al., 2000).

Although little is known about the properties of channels in interneuronal axons, the axonal surface area makes up a large fraction of the total surface area of the interneuron. To limit errors produced by choosing arbitrary parameters for the large surface area of the axonal membrane, and to speed computation, the axonal morphology was reduced to the point at which it enters the SLM region of the hippocampus. Because the axonal morphology was reduced, the passive properties were reoptimized in the reduced axon segments while keeping the somatic and dendritic passive properties fixed to the previously determined values (see Table $A 1$ in Appendix for values, available at www.jneurosci.org as supplemental material). This provided a correction for reducing the surface area. These reduced morphologies were used for all simulations.

Input resistance $\left(R_{\mathrm{m}}\right)$ was measured experimentally from each cell using a seal test protocol from -60 to $-65 \mathrm{mV}$. The steady-state current difference before and after the voltage step was used in combination with the known voltage difference to calculate $R_{\mathrm{m}}$ of each cell. The experimentally measured values for $R_{\mathrm{m}}$ were $349 \mathrm{M} \Omega$ for cell 1 and $506 \mathrm{M} \Omega$ for cell 2. With the optimized passive properties, as described above, the model interneurons have a $R_{\mathrm{m}}$ of $318 \mathrm{M} \Omega$ for cell 1 and $524 \mathrm{M} \Omega$ for cell 2 . Membrane time constants $\left(\tau_{\mathrm{m}}\right)$ measured for O-LM interneurons range in value from 33 to $66 \mathrm{~ms}$ (Gloveli et al., 2005). For the model interneurons, $\tau_{\mathrm{m}}$ values were $49 \mathrm{~ms}$ for cell 1 and $45 \mathrm{~ms}$ for cell 2 , which fall within this experimentally measured range.

A kinetic model for $I_{\mathrm{M}}$ was designed from values obtained from exper- iments. The model was based on three main experimental parameters. First, activation time constants were obtained by fitting single exponentials to linopirdine-sensitive current traces. Second, the deactivation kinetics of $I_{\mathrm{M}}$, with special attention given to the slow relaxation time constant of deactivation from -30 to $-50 \mathrm{mV}$, was modeled based on experimental data. Finally, the experimental somatic current voltage ( $I-V$ ) relationship of the $I_{\mathrm{M}}$-mediated component was used to estimate the density and voltage dependence of $g_{M}$ in the models. Tail currents were not consistently observed experimentally, resulting from possible space clamp and leak subtraction errors associated with the whole-cell recording configuration. However, the model explicitly incorporated the series resistance $\left(R_{\mathrm{s}}\right)$ and accounted for space-clamp errors related to the dendritic geometry of the neuron. This allowed $V_{1 / 2}$ and $k$ values to be adjusted in the model until the experimentally derived relationship between the command voltage and the somatically generated current was reproduced. The optimal values for $V_{1 / 2}$ and $k$ were $-27 \mathrm{mV}$ and 7 , respectively, in agreement with values reported in the literature (Jow and Wang, 2000; Prole et al., 2003). To simulate the effect of XE991, the conductance $g_{M}$ was set to 0 . The effect of the drug retigabine was simulated by shifting the $V_{1 / 2}$ of the steady-state activation curve from -27 to $-60 \mathrm{mV}$ (Wickenden et al., 2000) while keeping the conductance value the same as in the control cases.

The equations describing dynamics are summarized briefly here. First, the discrete version of the cable equation, an approximation to the original partial differential cable equation, describes the evolution of voltage in each compartment $k, V_{k}$ as follows:

$$
C \frac{d V_{\mathrm{k}}}{d t}=\sum_{\substack{n \\ n \neq k}} \gamma_{n, k}\left(V_{n}-V_{k}\right)-I_{\text {ionic, },},
$$

where $C=0.9 \mu \mathrm{F} / \mathrm{cm}^{2}$ for all compartments. The sum is taken over all compartments $n$ that are connected to compartment $k . \gamma_{n, k}$ is the internal conductance (reciprocal of axial resistivity; $1 / R_{\mathrm{a}}$ ) between the respective compartments. $I_{\text {ionic, } k}$ is the transmembrane ionic current for compartment $k$. Inward currents, which depolarize the membrane, are by convention, negative. For simplicity, the compartment subscript $k$ will be dropped from hereafter.

The term $I_{\text {ionic }}$ encompasses various ionic currents that were chosen from literature and experiments performed specifically on this interneuron subtype (Migliore et al., 1995; Zhang and McBain, 1995a,b; Maccaferri and McBain, 1996; Destexhe et al., 1998; Martina et al., 2000; Lien et al., 2002; Saraga et al., 2003). These currents include the traditional Hodgkin-Huxley sodium current, $I_{\mathrm{Na}}$, two (fast and slow) delayed rectifier $\mathrm{K}^{+}$currents, $I_{\mathrm{Kdrf}}$ and $I_{\mathrm{Kdrs}}$, the transient $\mathrm{K}^{+}$current, $I_{\mathrm{A}}$, the L-type calcium current, $I_{\mathrm{CaL}}$, the T-type calcium current, $I_{\mathrm{CaT}}$, the calciumactivated $\mathrm{K}^{+}$current, $I_{\mathrm{K}(\mathrm{Ca})}$, the hyperpolarization-activated cation current, $I_{\mathrm{h}}$, and the muscarinic $\mathrm{K}^{+}$current, $I_{\mathrm{M}}$. In each compartment and at each time, the current through a channel is proportional to its maximal conductance, $\bar{g}$, multiplied by its respective Hodgkin-Huxley gating variables, which include activation variables, $m$, and an inactivation variable, $h$, where applicable. Some channels do not inactivate and therefore the inactivation variable, $h$, is not included for these currents. $m$ and $h$ gating variables are representatives of the activation and inactivation variables for the particular ionic current and are not to be considered the same for the different currents.

The sum of the intrinsic membrane terms that, in each compartment, contribute to $I_{\text {ionic }}$ can be written as follows:

$$
\begin{aligned}
I_{\text {ionic }}=\bar{g}_{\mathrm{Na}} m^{3} h\left(V-E_{\mathrm{Na}}\right)+\bar{g}_{K d r f} m h\left(V-E_{K}\right)+\bar{g}_{K d r s} m h\left(V-E_{K}\right) \\
+\bar{g}_{K A} m h\left(V-E_{K}\right)+\bar{g}_{h} m\left(V-E_{h}\right)+\bar{g}_{M} m\left(V-E_{K}\right) \\
+\bar{g}_{\mathrm{CaL}} m^{2} h\left(\left[\mathrm{Ca}^{2+}\right]_{i}\right) \Gamma\left(V,\left[\mathrm{Ca}^{2+}\right]_{i},\left[\mathrm{Ca}^{2+}\right]_{o}\right) \\
+\bar{g}_{\mathrm{CaT}} m^{2} h \Gamma\left(V,\left[\mathrm{Ca}^{2+}\right]_{i},\left[\mathrm{Ca}^{2+}\right]_{o}\right)+\bar{g}_{K(\mathrm{Ca})} m\left(v,\left[\mathrm{Ca}^{2+}\right]_{i}\right)\left(V-E_{K}\right) \\
+\bar{g}_{K L}\left(V-E_{K}\right)+\bar{g}_{L}\left(V-E_{L}\right),
\end{aligned}
$$

where the reversal potential for sodium, $E_{\mathrm{Na}}=50 \mathrm{mV}$, for potassium, $E_{K}=-95 \mathrm{mV}$, and for the hyperpolarization-activated cation channel, 
$E_{h}=-32.9 \mathrm{mV}$. When referring to conductance $(g)$ throughout the text, this conductance is equal to the conductance density, $\bar{g}$, multiplied by the activation variable, $m$. See Table $A 2$ and $A 3$ (available at www. jneurosci.org as supplemental material) for conductance values, distributions, and kinetic equations.

The somatodendritic distribution of $I_{\mathrm{h}}$ is not known for interneurons. Because in hippocampal pyramidal neurons, $I_{\mathrm{h}}$ is distributed in both the soma and dendrites (Magee, 1998), we compared both somatic only and somatic-dendritic distributions of $I_{\mathrm{h}}$. The density of h-channels was adjusted in the two cases so as to produce the same "sag" when a hyperpolarizing step current of $100 \mathrm{pA}$ was applied to the soma (soma only, $5.00 \times 10^{-5} \mathrm{~S} / \mathrm{cm}^{2}$; somatodendritic, $\left.1.56 \times 10^{-6} \mathrm{~S} / \mathrm{cm}^{2}\right)$. Neither the spontaneous frequency ( $2.6 \mathrm{vs} 2.3 \mathrm{~Hz}$ ) nor the response of the cell to 100 $\mathrm{pA}$ of tonic depolarizing current injected into the soma (9.4 vs $9.2 \mathrm{~Hz})$ differed substantially between soma only and somatodendritic conditions, respectively. Because results were very similar for both distributions of $I_{\mathrm{h}}$, all subsequent simulations were performed with only somatic $I_{\mathrm{h}}$.

All VC simulations, excluding the -30 to $-50 \mathrm{mV}$ protocol, were done with only $I_{\mathrm{M}}$ and passive properties included in the models. All ion channels described above were included for the CC simulations. For the -30 to $-50 \mathrm{mV}$ VC simulations, the conductance values for $I_{\mathrm{Na}}, I_{\mathrm{K}(\mathrm{Ca})}$, $I_{\mathrm{CaT}}, I_{\mathrm{CaL}}$, and $I_{\mathrm{h}}$ were set to zero, simulating the experimental effects of TTX, $\mathrm{CdCl}_{2}$, and $5 \mathrm{~mm} \mathrm{CsCl}$.

\section{Results}

Laminar and cellular distribution of Kv7 channels in hippocampal interneurons

Although Kv7 channels have been detected in the somata of SO CA1 parvalbumin (PV)-positive interneurons (Cooper et al., 2001), probably corresponding to a subpopulation of basket cells (Somogyi and Klausberger, 2005), an additional interneuronal population of $\mathrm{PV}$-negative $\mathrm{Kv} 7+$ interneurons was found in SO that has not been identified either neurochemically or morphologically. To determine whether Kv7 subunits were present in anatomically identified interneuron populations, we used the socalled GIN mice, in which GFP is expressed predominantly in somatostatin-positive interneurons (Oliva et al., 2000). In these mice, GFP + SO cells in CA1 hippocampus are comprised entirely of O-LM cells (Oliva et al., 2000), an abundant and well characterized SO cell type (Maccaferri and Lacaille, 2003; Maccaferri, 2005). Although GFP + cells are present in other hippocampal layers, these cells represent SOM + interneurons, the axons of which also ramify exclusively in SLM (Oliva et al., 2000).

Kv7.2 immunoreactivity was strong in the somata of pyramidal cells but also in interneurons in SO (Fig. $1 B$ ). A subset of $\mathrm{GFP}+\mathrm{SO}$ cells expressed Kv7.2+ (Fig. $1 A, B$, arrows). In addition, Kv7.2 expression was detected in the dendrites of GFP+ SO cells (Fig. $1 C, D$, filled arrows). Similar labeling of Kv7.3 in both soma and dendrites was detected in GFP+ SO cells (Fig. $1 E-H$ ). Quantification of Kv7 subunits in GFP+ cells revealed that as a population, $39.7 \pm 6.3 \%$ (150 of 377 ) of GFP + SO cells were Kv7.2 positive. However, GFP+ SR/SLM interneurons did not express Kv7.2 to the same extent ( $16.8 \pm 7.3 \%, 32$ of 191 cells; $p<$ $0.05 ; n=4)$. For Kv7.3 subunits, a similar distribution was observed: Kv7.3 labeling was detected in $34.3 \pm 4.0 \%$ ( 143 of 417 ) of GFP + SO cells but only $16.14 \pm 4.1 \%$ (36 of 223 ) of GFP+ SR/SLM cells $(p<0.01 ; n=4)$. The expression of Kv7.2 and Kv7.3 subunits to similar extents within SO and SR/SLM GFP+ cell populations are consistent with the idea that Kv7.2/Kv7.3 heteromers form a common channel composition in the hippocampus (Cooper et al., 2000; Hadley et al., 2003; Delmas and Brown, 2005). Axonal labeling of Kv7.2 and Kv7.3 was essentially absent in SLM, where the axons of GFP+ cells form a dense plexus (Fig. S1, available at www.jneurosci.org as supplemental material). In summary, immunocytochemical labeling of Kv7.2

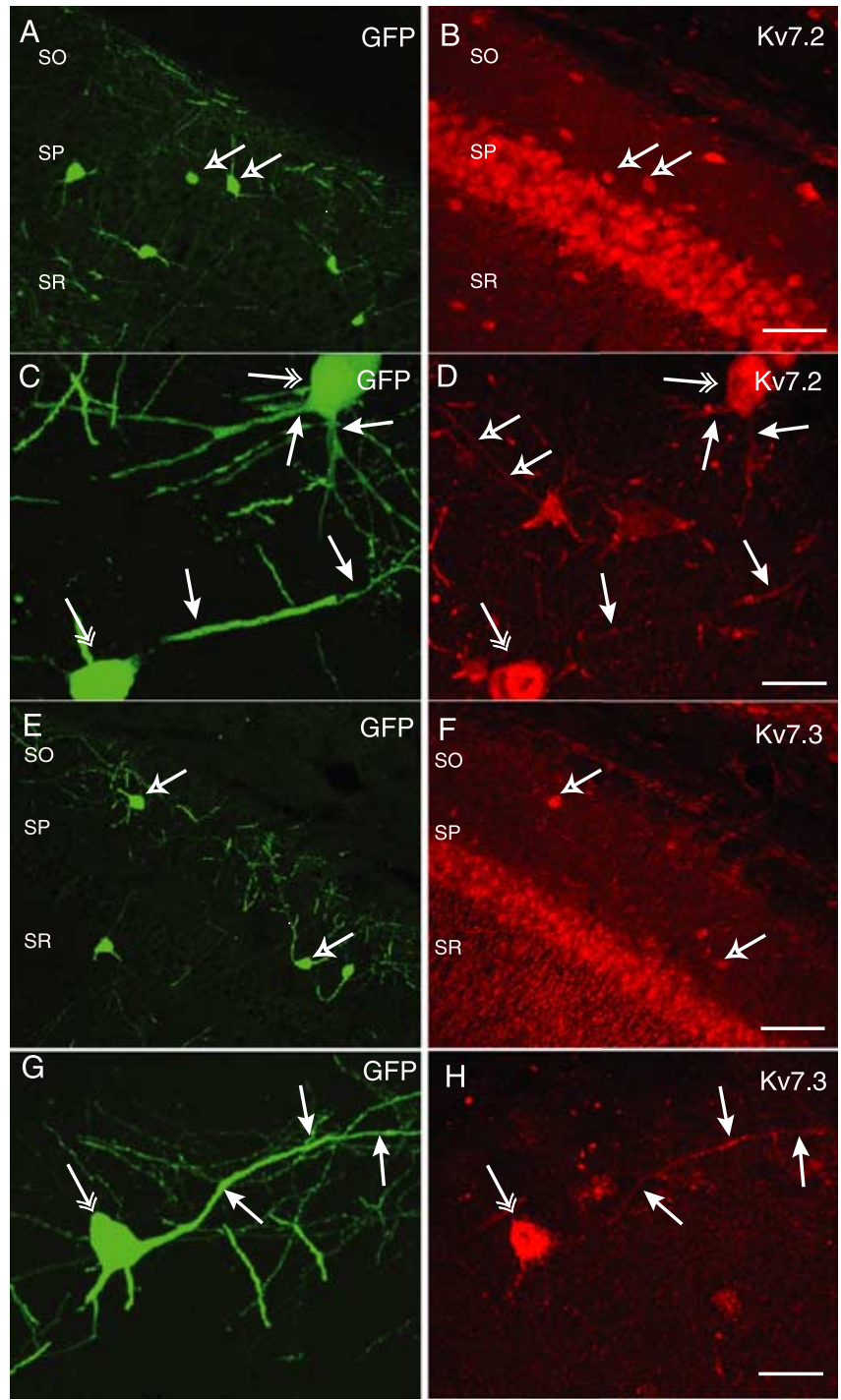

Figure 1. Somatodendritic expression of Kv7.2 (A-D) and Kv7.3 (E-H) in GFP + hippocampal interneurons. Confocal images of CA1 hippocampal slices from GIN transgenic mice, which express GFP in somatostatin-positive CA1 hippocampal interneurons in S0, SP, and stratum radiatum (SR), are shown. GFP expression $(\boldsymbol{A})$ and Kv7.2+ immunoreactivity $(\boldsymbol{B})$ reveal colocalization of Kv7.2 in a subpopulation of GFP + cells (arrows). GFP + cells in S0 exhibit Kv7.2 immunoreactivity on somata ( $\boldsymbol{C}$, double arrows) and dendrites ( $\boldsymbol{C}, \boldsymbol{D}$, single filled arrows). Open arrows in $\boldsymbol{D}$ indicate a Kv7.2-immunoreactive dendrite from a GFP-negative interneuron. GFP+ interneurons $(\boldsymbol{E})$ also colocalize with Kv7.3 immunoreactivity ( $\boldsymbol{F}$, arrows). In a GFP $+\mathrm{S} 0$ interneuron $(\boldsymbol{G})$, somatic $(\boldsymbol{H}$, double arrow) and dendritic $(\boldsymbol{H}$, single arrows) Kv7.3 immunoreactivity was also apparent. Scale bars: $\boldsymbol{B}, \boldsymbol{F}, 100 \mu \mathrm{m} ; \boldsymbol{D}, \boldsymbol{H}, 25 \mu \mathrm{m}$.

and Kv7.3 subunits was localized to somatodendritic regions of CA1 SO interneurons and is more abundantly expressed in GFP + SO cells (most likely O-LM cells) than in other GFP + cell populations.

\section{Electrophysiological detection of Kv7 channels in SO interneurons}

Using a protocol that reveals $I_{\mathrm{M}}$ through its distinct voltage dependence and time course of deactivation from other $\mathrm{K}^{+}$channels (Lamas et al., 1997; Schnee and Brown, 1998), we determined whether $I_{\mathrm{M}}$ could be revealed in SO interneuron populations. In this protocol, the cell was held at $-30 \mathrm{mV} ; 1 \mathrm{~s}$ long, $-20 \mathrm{mV}$ steps were introduced every $15 \mathrm{~s}$ (Fig. 2). Under control conditions, a step to $-50 \mathrm{mV}$ forced deactivation of a 


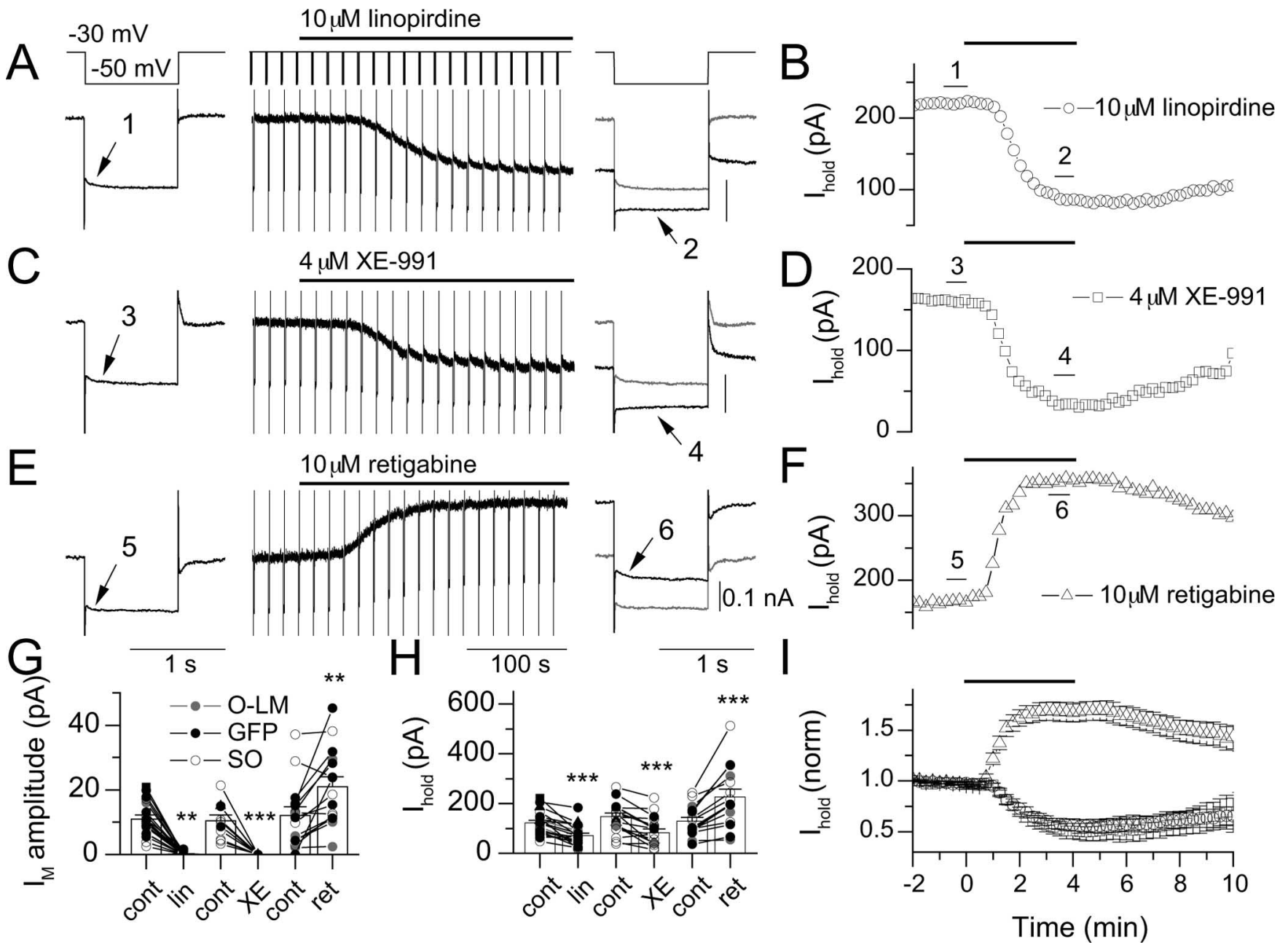

Figure 2. Detection of $I_{M}$ in $S 0$ interneurons using linopirdine, $X E-991$, and retigabine. In VC, a step was applied from -30 to $-50 \mathrm{mV}$ at $15 \mathrm{sintervals.} \mathrm{After} \mathrm{a} 2 \mathrm{~min}$ baseline period, a 4 min application of $10 \mu \mathrm{m}$ linopirdine $(\boldsymbol{A}, \boldsymbol{B}), 4 \mu \mathrm{M} X \mathrm{E}-991(\boldsymbol{C}, \boldsymbol{D})$, or $10 \mu \mathrm{m}$ retigabine $(\boldsymbol{E}, \boldsymbol{F})$ was applied to the bath. Traces enumerated in $\boldsymbol{A}, \boldsymbol{C}$, and $\boldsymbol{E}$ are the average of three traces within a $45 \mathrm{~s}$ window as indicated by the bars in $\boldsymbol{B}, \boldsymbol{D}$, and $\boldsymbol{F}$, respectively. Traces were filtered at $500 \mathrm{~Hz}$ for display. Control traces (gray) are overlaid for comparison with drug conditions (black). $I_{\mathrm{M}}$ amplitudes ( $\boldsymbol{G}$ ) and $I_{\text {hold }}(\boldsymbol{H})$ at $-30 \mathrm{mV}$ for mean data (columns) and individual cells (points) for linopirdine $(n=19)$, XE-991 (XE; $\left.n=11\right)$, and retigabine (ret; $\left.n=15\right)$ conditions are shown. Each condition in $\mathbf{G}$ and $\boldsymbol{H}$ was paired with its initial control value obtained in a $45 \mathrm{~s}$ window before the onset of application of the drug. GFP + SO cells, anatomically identified 0-LM cells, and unidentified SO cells are indicated by black symbols, gray symbols, and open symbols, respectively. I, Time course of changes in I hold during application of linopirdine (circles), XE-991 (squares), or retigabine (triangles), normalized to the initial $I_{\text {hold }}$ before drug application.

slowly relaxing outward current that decayed with a time constant of $\sim 106 \mathrm{~ms}$ (Fig. $2 \mathrm{~A}$ ), consistent with the presence of $I_{\mathrm{M}}$. The amplitude of the single exponential fit, in this case $20 \mathrm{pA}$, was used as an index of how much $I_{\mathrm{M}}$ was present. After repolarization to $-30 \mathrm{mV}, I_{\mathrm{M}}$ was observed to reactivate, although this observation was not always in a symmetrical manner because of the reactivation of one or more additional conductances present. After obtaining a 2-3 min baseline, the Kv7 antagonist linopirdine $(10 \mu \mathrm{M})$ was added to the bath, causing a complete loss of measurable $I_{\mathrm{M}}$ over the course of $4 \mathrm{~min}$ (Fig. $2 \mathrm{~A}$ ), accompanied by a reduction in $I_{\text {hold }}$ from 221 to 86 pA (Fig. $2 B$ ). As demonstrated in Figure 2, $C$ and $D$, a similar time course and extent of block was observed using the Kv7 antagonist XE-991 (4 $\mu \mathrm{M})$, which abolished the $21 \mathrm{pA} I_{\mathrm{M}}$-mediated current detected in control conditions and reduced $I_{\text {hold }}$ from 160 to $21 \mathrm{pA}$ at $-30 \mathrm{mV}$. In contrast, the Kv7 channel opener retigabine had the reverse effect, enhancing the amplitude of the $I_{\mathrm{M}}$-mediated relaxation from 18 to $32 \mathrm{pA}$ (Fig. $2 E$ ), which was accompanied by an increase in $I_{\text {hold }}$ from 167 to 355 pA (Fig. $2 F$ ).

Distributions of $I_{\mathrm{M}}$ amplitude and drug-induced changes in
$I_{\text {hold }}$ at $-30 \mathrm{mV}$ for individual cells and the mean are plotted in Figure $2 G-I$. In linopirdine experiments, a measurement of $I_{\mathrm{M}}$ amplitude could be obtained in 19 of 27 (70.4\%) SO interneurons; the average $I_{\mathrm{M}}$ amplitude was $11 \pm 1.2 \mathrm{pA}$, which decayed with an average time constant of $193 \pm 57 \mathrm{~ms}$. After $4 \mathrm{~min}$ application of $10 \mu \mathrm{M}$ linopirdine at $-30 \mathrm{mV}, I_{\mathrm{M}}$ amplitude was abolished to $0.1 \pm 0.1 \mathrm{pA}$ (Fig. $2 G)\left(n=19 ; p=4 \times 10^{-8}\right)$, and $I_{\text {hold }}$ was reduced from $122 \pm 11$ to $71 \pm 9$ pA (Fig. $2 H)(n=19 ; p=$ $\left.7 \times 10^{-6}\right)$. The initial $I_{\mathrm{M}}$ amplitude and linopirdine-induced change in $I_{\text {hold }}$ were correlated ( $p=0.013$ ). In eight cells, $I_{M}$ was not detected; however, linopirdine produced a smaller but significant decrease in $I_{\text {hold }}$ at $-30 \mathrm{mV}(-17.5 \pm 3.8 \mathrm{pA} ; p=0.002)$. Similarly, in experiments in which XE-991 was used, $I_{M}$ was detected in 11 of $17(64.7 \%)$ SO cells (mean, $10.5 \pm 1.7 \mathrm{pA})$. In the presence of XE-991, $I_{\mathrm{M}}$ was completely abolished (Fig. $\left.2 G\right)(p=$ $0.0001 ; n=11)$, and the mean $I_{\text {hold }}$ at $-30 \mathrm{mV}$ decreased from $146 \pm 16$ to $82 \pm 16$ pA (Fig. $2 H)(p=0.0002 ; n=11)$. A significant correlation was also seen between $I_{\mathrm{M}}$ amplitude and the shift in $I_{\text {hold }}$ induced by XE-991 ( $p=0.0008$; $\left.n=11\right)$. Retigabine increased the mean $I_{\mathrm{M}}$ amplitude from $12.1 \pm 2.6$ to 
$21.0 \pm 3.1 \mathrm{pA}($ Fig. $2 G)(p=0.002 ; n=$ 15) and the mean $I_{\text {hold }}$ at $-30 \mathrm{mV}$ from $128 \pm 16$ to $227 \pm 32 \mathrm{pA}$ (Fig. $2 H)(p=$ $0.0001 ; n=15)$. The initial $I_{\mathrm{M}}$ amplitude and the magnitude of the increase in $I_{\text {hold }}$ at $-30 \mathrm{mV}$ by retigabine were correlated $(p=0.016 ; n=15)$. Figure $2 I$ plots the mean $I_{\text {hold }}$ at $-30 \mathrm{mV}$, normalized to the initial $I_{\text {hold }}$, for each of the three drug conditions. Note that linopirdine and XE-991 overlap well in both magnitude and time course of inhibition of $I_{\text {hold }}$ at $-30 \mathrm{mV}$. In summary, using three different modulators of Kv7 channels, these data reveal the presence of $I_{\mathrm{M}}$ in SO interneurons.

\section{Tetraethylammonium sensitivity of interneuronal $I_{M}$}

In recombinant and native systems, Kv7.2containing subunits are selectively blocked by submillimolar concentrations of tetraethylammonium (TEA) (Hadley et al., 2000, 2003; Shah et al., 2002). To determine whether Kv7.2-containing channels contributed to $I_{\mathrm{M}}$ in SO interneurons, 0.5 mM TEA was applied to SO interneurons held at $-30 \mathrm{mV}$ (Fig. 3). For these experiments, SO recordings were limited to those in which $I_{\mathrm{M}}$ amplitude was detected (Fig. 3A). A 4 min application of $0.5 \mathrm{~mm}$ TEA blocked the $I_{\mathrm{M}}$ amplitude from $26.9 \pm 6.9$ to $13.1 \pm 4.4 \mathrm{pA}(p=0.002$; $n=10$ ) (Fig. $3 B$ ) and reduced $I_{\text {hold }}$ at -30 $\mathrm{mV}$ (from $160.3 \pm 39.0$ to $132.2 \pm 37.4$ $\left.\mathrm{pA} ; p=2.6 \times 10^{-5} ; n=10\right)$ (Fig. $3 C$ ). We then asked whether $4 \mu \mathrm{M}$ XE-991 could occlude the effects of TEA on $I_{\mathrm{M}}$ amplitude and $I_{\text {hold }}$. Application of $4 \mu \mathrm{M}$ XE-991 inhibited $I_{\mathrm{M}}(38.6 \pm 6.9$ to $6.2 \pm 1.1 \mathrm{pA})$ and reduced $I_{\text {hold }}$ at $-30 \mathrm{mV}(246.3 \pm 26.2$ to $192.5 \pm 29.4 \mathrm{pA} ; p=0.0006)$, but subsequent application of $0.5 \mathrm{~mm}$ TEA plus 4 $\mu \mathrm{M}$ XE-991 did not produce a further reduction in $I_{\mathrm{M}}$ amplitude $(5.8 \pm 1.6$ to $5.7 \pm 2.0 \mathrm{pA} ; p=0.97 ; n=7$ ) (Fig. $3 B$ ) or $I_{\text {hold }}(188.9 \pm 41.2$ to $185.5 \pm 35.6 \mathrm{pA} ; p=$ $0.86 ; n=7$ ) (Fig. $3 C$ ). These findings suggest that a substantial fraction of $I_{\mathrm{M}}$ is carried by TEA-sensitive, Kv7.2-containing subunits.

\section{Morphology of $I_{\mathrm{M}^{-}}$-containing SO interneurons}

In 48 cells from wild-type animals in which sufficient biocytin filling of the axon permitted identification of the cell type, 43 $I_{\mathrm{M}}$-containing cells were found to be O-LM cells (89.6\%), consistent with O-LM cells being a commonly encountered cell type in SO (Maccaferri, 2005). Other $I_{\mathrm{M}}$-containing cells included four cells in which the axon terminated primarily in the pyramidal cell layer $(8.3 \%)$, which most likely correspond to basket cells (Fig. 4, cell 4 ), and one cell in which the axon ramified primarily in SO 0 -LM cells.

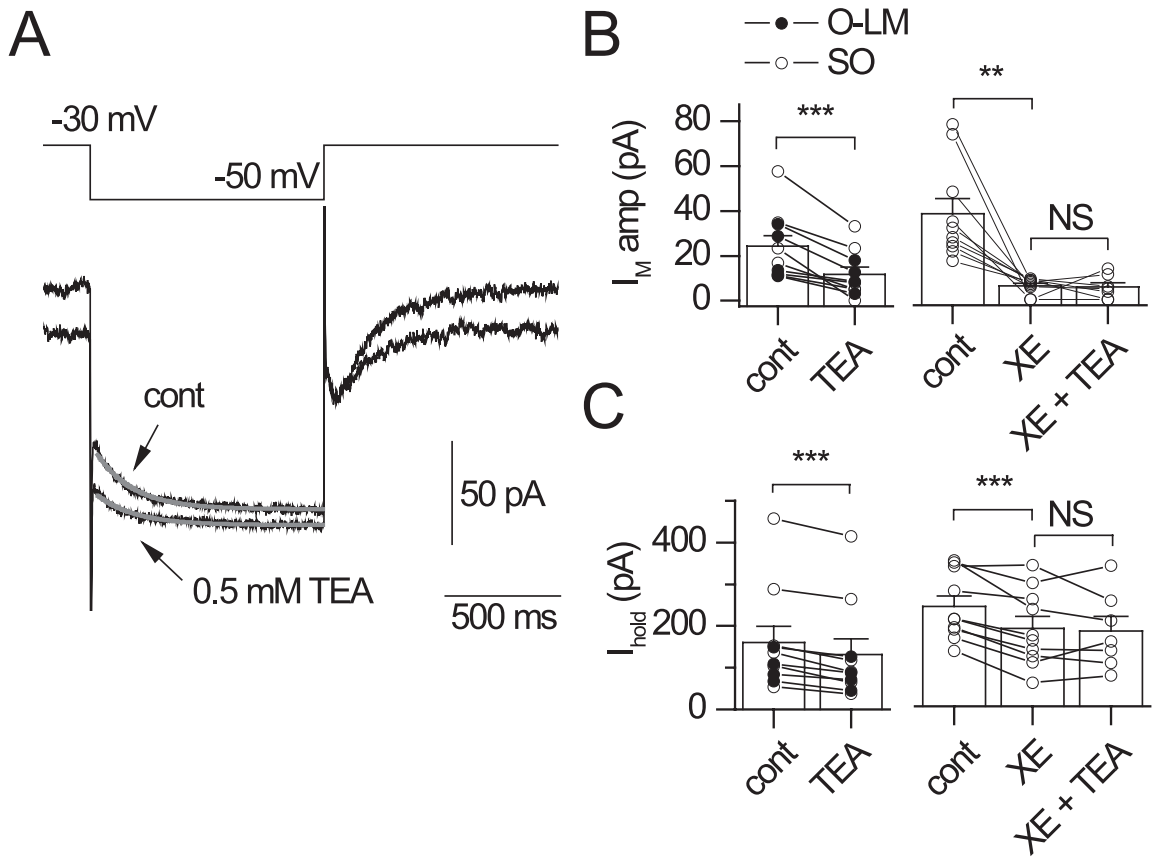

Figure 3. TEA sensitivity of interneuron $I_{M}$. TEA $(0.5 \mathrm{~mm})$ was bath applied to $S 0$ interneurons or after inhibition of $I_{M}$ with $4 \mu \mathrm{M}$ XE-991 (XE). $A$, Current response to a $-20 \mathrm{mV}$ step from $-30 \mathrm{mV}$ under control conditions (cont) and after a 4 min application of $0.5 \mathrm{~mm}$ TEA. Gray lines in $\boldsymbol{A}$ indicate single exponential fits from which $/ \mathrm{M}$ amplitude was obtained. Plots of $I_{\mathrm{M}}$ amplitude $(\boldsymbol{B})$ and $I_{\text {hold }}(C)$ at $-30 \mathrm{mV}$ for each condition $(n=10)$ are shown. Filled symbols indicate recordings from morphologically identified

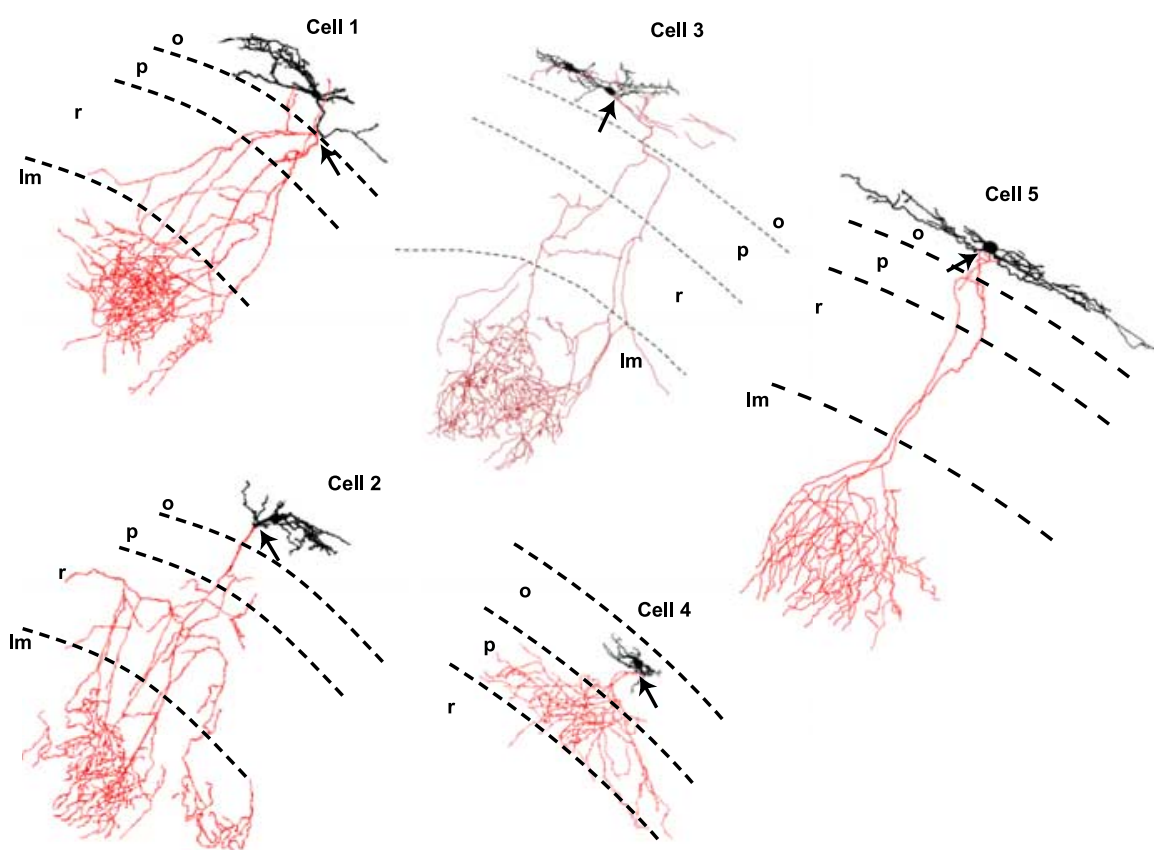

Figure 4. Anatomical identification of $I_{M}$-containing $S 0$ interneurons. Neurolucida reconstructions of 40 -LM cells (cells $\left.1-3,5\right)$ and one putative basket cell (cell 4 ) are shown. Strata are labeled stratum oriens (0), pyramidale (p), radiatum ( $r$ ), and lacunosum moleculare $(\mathrm{Im})$. Cells 1 and 2 were used in subsequent simulations. Arrows denote where the axon emerged from the dendrite (cells 1 and 2) or cell body (cells 3-5).
(2.1\%). Representative Neurolucida reconstructions of five $I_{\mathrm{M}^{-}}$ containing cells are shown in Figure 4. As previously described in rats (Martina et al., 2000), O-LM cell morphologies featured cells in which the axon originated either from a proximal dendrite (cells 1,2) or the soma (cells 3, 5). 
In a subset of recordings, we recorded from $27 \mathrm{GFP}+\mathrm{SO}$ cells. In several cells in which sufficient axonal labeling allowed the unambiguous identification of the cell type, GFP+ SO cells were found to project to LM, as reported previously (Oliva et al., 2000). Consistent with the heterogeneity in immunocytochemical detection of Kv7.2/Kv7.3 in GFP+ cell populations (Fig. 1), the magnitude of $I_{\mathrm{M}}$ (Fig. $2 G$, black symbols) and change in $I_{\text {hold }}$ (Fig. $2 \mathrm{H}$, black symbols) fell across a 2-20 pA range in recorded GFP+ SO cells. In addition, in 4 of $17(23.5 \%) \mathrm{GFP}+\mathrm{SO}$ cells, an $I_{\mathrm{M}}$ amplitude was not detected (data not shown).

\section{$I_{M}$-mediated outward currents in SO interneurons}

After sustained depolarization, hippocampal CA1 SO interneurons produce large outward $\mathrm{K}^{+}$currents (Zhang and McBain, 1995b; Martina et al., 1998; Lien et al., 2002). In addition to a transient $I_{\mathrm{A}}$-type conductance, the outward conductance is comprised of a sustained component thought to be carried by Kv3like channels and to a smaller extent by $\mathrm{Ca}^{2+}$-sensitive conductances (Zhang and McBain, 1995b; Lien et al., 2002). Importantly, in previous studies, Kv3-like outward currents in SO interneurons were isolated based on their TEA sensitivity (Zhang and McBain, 1995b; Martina et al., 1998; Lien et al., 2002), which we now show will also block interneuronal $I_{M}$ in these neurons (Fig. 3). Moreover, the same protocols used to activate the sustained outward current would be expected to activate $I_{\mathrm{M}}$ (Martina et al., 1998; Lien et al., 2002).

To address whether an $I_{\mathrm{M}}$-like conductance was present in the sustained outward current of hippocampal CA1 SO interneurons, we introduced a large depolarizing voltage step from -60 $\mathrm{mV}$ and determined to what extent $I_{\mathrm{M}}$ antagonists blocked the outward current. As illustrated in Figure $5 \mathrm{~A}$ (inset), a $+100 \mathrm{mV}$ voltage step command from $-60 \mathrm{mV}$ generated an outward current of $7.8 \mathrm{nA}$ amplitude, which was reduced to $6.8 \mathrm{nA}$ after incubation of the $I_{M}$ antagonist XE-991 $(8 \mu \mathrm{M})$. Digital subtraction of the control current from the current obtained in the presence of XE-991 yielded a $\sim 1 \mathrm{nA} I_{\mathrm{M}}$-mediated current that was $13.6 \%$ of the total outward current. As revealed by application of XE-991 or linopirdine, plots of individual and pooled isolated $I_{\mathrm{M}}$ outward current amplitudes (Fig. 5A) and the fractional contribution of $I_{\mathrm{M}}$ to the total outward current (Fig. $5 B$ ) are shown. With increasing concentration of XE-991, increasingly larger XE991-sensitive components of the outward current were revealed, as well as the fraction of cells exhibiting $I_{\mathrm{M}}$-mediated currents. Linopirdine $(10 \mu \mathrm{M})$ also revealed large $I_{\mathrm{M}}$-mediated outward currents $(1590 \pm 374 \mathrm{pA})$ in six of six cells $(p=0.008$, compared with vehicle), comprising $24.2 \pm 5.5 \%$ of the total outward current.

In a separate set of experiments, we examined the time course of activation of the $I_{\mathrm{M}}$-mediated current by applying a series of increasingly more depolarizing voltage steps in the absence and presence of $10 \mu \mathrm{M}$ linopirdine (Fig. 5C). After delivering a voltage step from -60 to $-25 \mathrm{mV}$, the isolated $I_{\mathrm{M}}$ activated with an average time constant of $80.0 \pm 10.7 \mathrm{~ms}$, consistent with the relatively slow time course of activation of the $I_{\mathrm{M}}$-mediated current (Selyanko and Brown, 1999; Shah et al., 2002). However, with increasingly stronger levels of depolarization, the time course of $I_{\mathrm{M}}$ activation decreased (Fig. $5 D$, filled circles) as the amplitude of the $I_{\mathrm{M}}$ outward current increased (Fig. $5 D$, filled squares). However, the time course of activation of the linopirdine-insensitive component of the outward current (Fig. $5 D$, open circles) was faster at test voltages between -25 and +35 $\mathrm{mV}(p<0.05 ; n=6)$, indicating that linopirdine-sensitive and
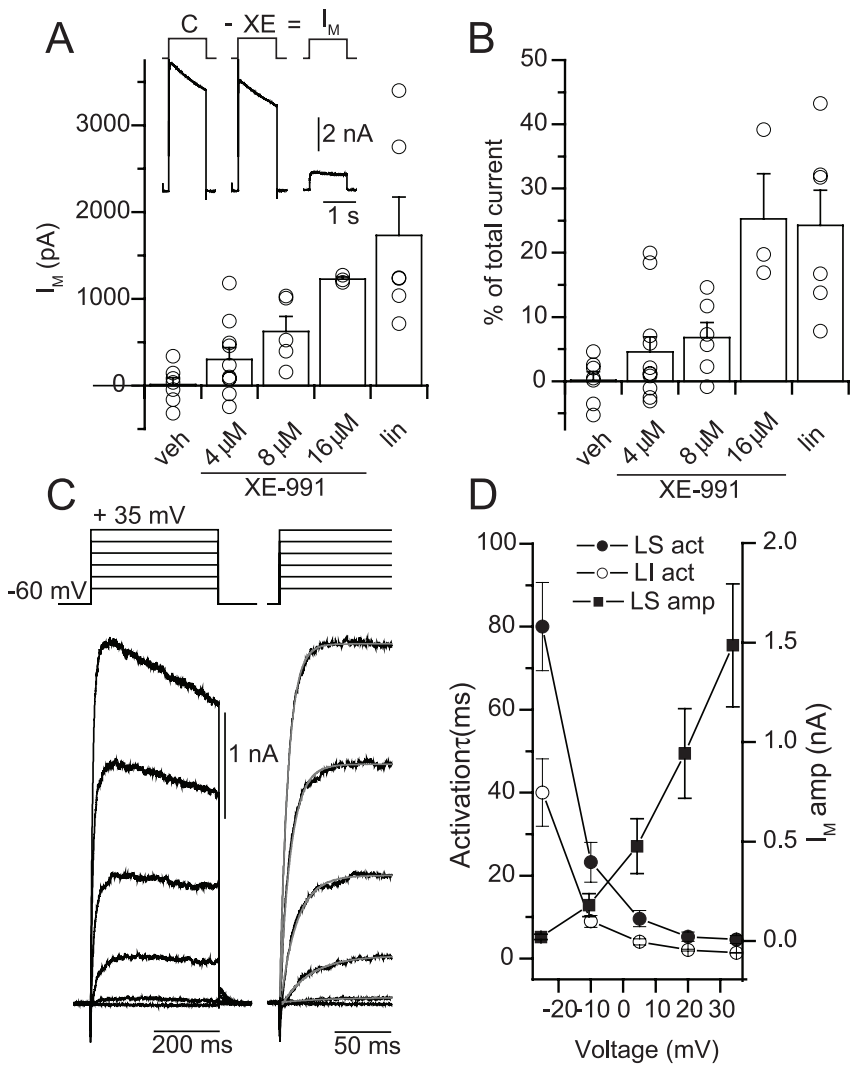

Figure 5. XE-991- and linopiridine-sensitive components of outward currents in S0 interneurons. $\boldsymbol{A}$, Inset, Digital subtraction of the outward current generated by a $+100 \mathrm{mV}$ voltage step command from $-60 \mathrm{mV}$ in control (C) from that generated after 10 min incubation in $8 \mu \mathrm{m}$ XE-991 (XE) yields the isolated outward current mediated by $I_{\mathrm{M}}$. Dose dependence of $I_{\mathrm{M}}$ antagonist effect, plotted as $I_{M}$ amplitude $(\boldsymbol{A})$ and as a percentage $(\boldsymbol{B})$ of the total outward current for vehicle (veh), 4-16 $\mu \mathrm{m}$ XE-991, and $10 \mu \mathrm{m}$ linopirdine (lin) conditions. Recording stability was first ascertained in the absence of antagonists (vehicle). Recordings in which $\Delta R_{\mathrm{s}}$ was $<3 \%$ after 10 min of whole-cell recording generated subtracted currents that were typically \pm 300 $\mathrm{pA}$ (mean $43 \pm 86 \mathrm{pA} ; n=7$ ), a negligible amount $(0.2 \pm 1.3 \%$ ) of the total outward current $(7.5 \pm 0.7 \mathrm{nA})$. Experiments with $I_{\mathrm{M}}$ antagonists used the same criteria for recording stability and time point in the recording (at $10 \mathrm{~min}$ after application of antagonists). The $I_{\mathrm{M}}$-mediated current was significantly outside of the distribution of the vehicle for 4 of 11 cells in $4 \mu \mathrm{M} X \mathrm{X}-991$ $(733 \pm 162 \mathrm{pA} ; p=0.01)$, four of six cells in $8 \mu \mathrm{m} X \mathrm{XE}-991(742 \pm 164 \mathrm{pA} ; p=0.01)$, three of three cells in $16 \mu \mathrm{m}$ XE-991 (1227 $\left.\pm 24 \mathrm{pA} ; p=4 \times 10^{-6}\right)$, and six of six cells in $10 \mu \mathrm{m}$ linopirdine (1590 $\pm 374 p A ; p=0.008)$. C, Linopirdine-sensitive outward currents generated in response to a family of voltage steps from $-60 \mathrm{mV}$ to $+35 \mathrm{mV}$. Right, Expanded region showing single exponential fits (gray) to the rise of the outward current. D, Time constant of activation of the linopirdine-sensitive component (LS act; filled circles), the linopirdineinsensitive component ( $\mathrm{LI}$ act; open circles), and the amplitude of the linopirdinesensitive component (LS amp; filled squares) plotted versus command voltage for a population of six SO cells.

-insensitive components of the outward current were kinetically distinct from one another.

In addition, we examined how $I_{\mathrm{M}}$ antagonists altered deactivation of the outward current (Fig. 6). In control conditions, depolarization to a command potential of $+40 \mathrm{mV}$ generated a $6.4 \mathrm{nA}$ outward current, which, after stepping back to $-22.5 \mathrm{mV}$, generated a complex time course of deactivation that was well described by three exponentials (Fig. 6A, gray). Digital subtraction of the exponential curves obtained in control and in the presence of XE-991 described the deactivation of the $I_{\mathrm{M}^{-}}$ mediated component well (Fig. $6 B$ ). Inspection of the amplitudes (Fig. 6C,D), time constants (Fig. 6E,F), and percentages of each component (Fig. 6G,H) revealed that the XE-991-sensitive current is predominantly composed of an intermediate time con- 

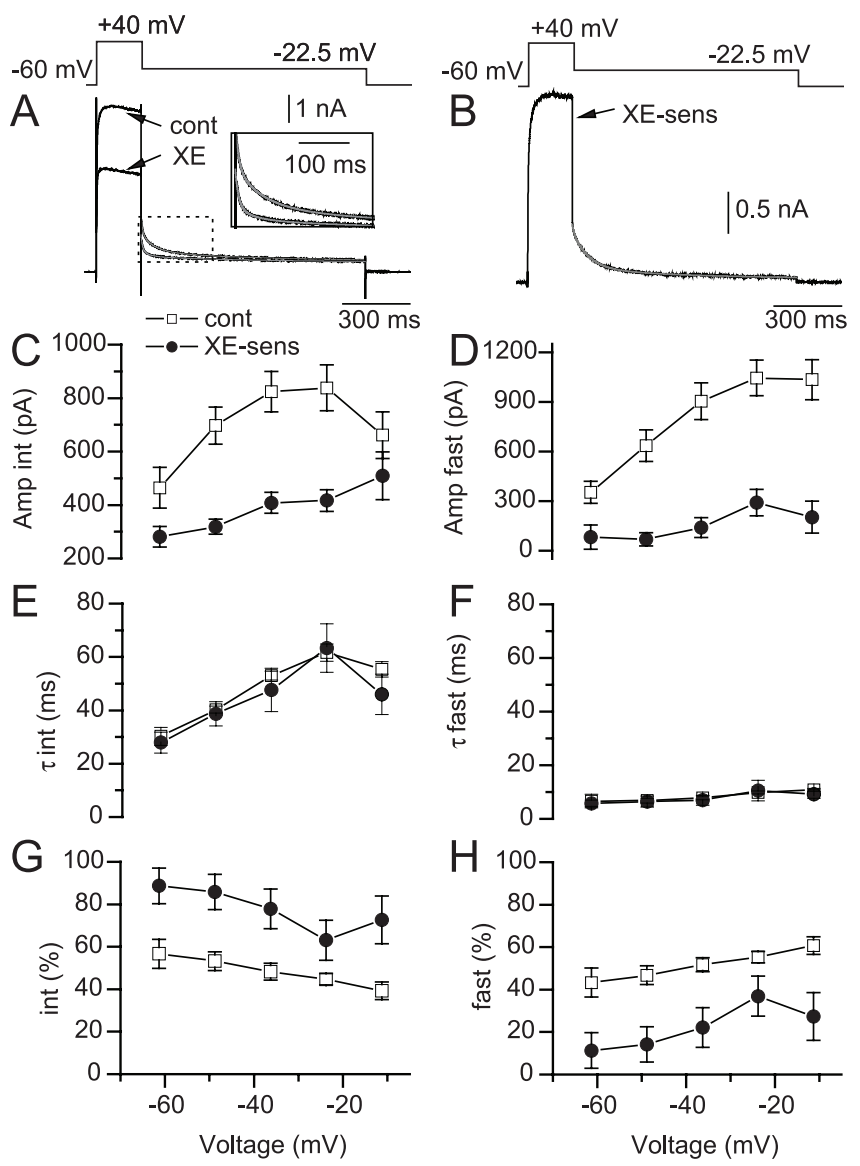

Figure 6. $I_{M}$ underlies an intermediate component of outward current deactivation. $\boldsymbol{A}$, Triple exponential fits (gray) to the deactivation of the outward current after deactivation of -22.5 $\mathrm{mV}$ in control (cont) or in the presence of $4 \mu \mathrm{m}$ XE-991 (XE). Inset, Expanded region showing that the trace obtained in the presence of XE-991 deactivates faster than the trace in control conditions. $\boldsymbol{B}$, XE-991-senstive (XE-sens) trace (black) and fit (gray) obtained via digital subtraction of the traces and fits in $\boldsymbol{A}$. Amplitudes $(\boldsymbol{C}, \boldsymbol{D})$, time constants $(\boldsymbol{E}, \boldsymbol{F})$, and percentages ( $\boldsymbol{G}$, $\boldsymbol{H}$ ) of each component, plotted against the test potential for control (open squares) and XE-991sensitive traces (filled circles). Percentages in $\boldsymbol{G}$ and $\boldsymbol{H}$ are calculated from the combined amplitude (amp) of fast and intermediate (int) components.

stant of deactivation (Fig. 6G). The fast component (Fig. 6D,F), which probably reflects deactivation of Kv3 channels, was relatively insensitive to XE-991 (Fig. $6 \mathrm{H}$ ). Similar results were obtained using $10 \mu \mathrm{M}$ linopirdine $(n=8$; data not shown). Although dendritic filtering will influence the kinetics of deactivation of $I_{\mathrm{M}}$, these results nevertheless show that $I_{\mathrm{M}}$ mediates a substantial fraction of the intermediate component present in the deactivation of the outward current.

Although we show that the outward currents isolated by Kv7 antagonists can be distinguished from the faster (presumably delayed rectifier) component of the outward current based on both their activation (Fig. 5D) and deactivation (Fig. 6C-H) time courses, the observation that the linopirdine-sensitive component activates more rapidly at depolarized potentials (Fig. 5D) than appreciated in recombinant Kv7 channels (Wang et al., 1998) raised the possibility that delayed rectifiers may have some affinity for Kv7 antagonists. Slow-delayed rectifier channels in CA1 pyramidal cells, which are primarily composed of Kv2 channels (Martina et al., 1998), have no appreciable affinity for linopirdine at $10 \mu \mathrm{M}$ (Schnee and Brown, 1998). However, whether fast delayed rectifiers, which are primarily composed of
Kv3 channels in SO interneurons (Martina et al., 1998), have any affinity for Kv7 antagonists is not known.

We tested the effects of linopirdine or XE-991 on recombinant Kv3 channels expressed in HEK293 cells. As shown in Fig. S2 (available at www.jneurosci.org as supplemental material), neither linopirdine nor XE-991 at $20 \mu \mathrm{M}$ substantially altered the amplitude of Kv3.1- or Kv3.2-mediated outward currents. In addition, we performed a subset of recordings from $\mathrm{SO}$ interneurons in the continuous presence of $1 \mathrm{mM} 4-\mathrm{AP}$, which blocks the majority of Kv3-mediated current (Fig. S2, available at www. jneurosci.org as supplemental material) (Lien et al., 2002). Under these conditions, $10 \mu \mathrm{M}$ linopirdine attenuated $I_{\mathrm{M}}$ amplitude after stepping from -30 to $-50 \mathrm{mV}(10.9 \pm 2.3$ to $0.3 \pm 0.3 \mathrm{pA}$; $p=0.01)$ and induced changes in $I_{\text {hold }}$ at $-30 \mathrm{mV}(102 \pm 16$ to $68 \pm 16 \mathrm{pA} ; p=0.04 ; n=5)$, similar to that seen in the absence of 4-AP. After strong depolarization to $+20 \mathrm{mV}$, rapidly activating $(\tau=4.5 \pm 1.8 \mathrm{~ms})$, linopirdine-sensitive outward currents $(1024 \pm 327 \mathrm{pA} ; n=5)$ were observed in the presence of $1 \mathrm{~mm}$ 4-AP. Therefore, we conclude that linopirdine- and XE-991sensitive components of the outward current are indeed carried by Kv7 channels, and that the magnitude and kinetics of the $I_{\mathrm{M}}$-mediated outward current are unlikely to be substantially contaminated by a Kv3-mediated outward current component.

\section{Effects of $I_{M}$ modulators on AP firing pattern}

As an initial assessment of the physiological consequences of $I_{\mathrm{M}}$, we took advantage of the observation that many SO interneurons fire spontaneously (McBain et al., 1994; Zhang and McBain, 1995a). Spontaneous firing was monitored as action currents in loose-patch configuration, a noninvasive approach that yields excellent signal-to-noise (Fig. 7A). After bath application of $8 \mu \mathrm{M}$ XE-991, the mean time interval between APs decreased from 0.44 to $0.24 \mathrm{~s}$ (Fig. $7 B$ ), corresponding to an $82 \%$ increase in AP frequency. In a population of nine cells [three cells using XE-991 (8 $\mu \mathrm{M})$ and six cells using linopirdine $(20 \mu \mathrm{M})]$, AP frequency increased by $90.9 \%$ ( $p=0.039$ ), suggesting that Kv7 channels influence spontaneous firing frequency in SO interneurons.

Whole-cell current-clamp recordings were then performed in GFP+ SO cells (Fig. 7C-E). Consistent with loose-patch recordings, $20 \mu \mathrm{M}$ linopirdine increased the average firing frequency from $1.0 \pm 0.7$ to $4.5 \pm 1.5 \mathrm{~Hz}$ (Fig. $7 C)(n=11 ; p=0.015)$, which was accompanied by a depolarization from $-57.7 \pm 1.5$ to $-53.1 \pm 1.8 \mathrm{mV}(n=11 ; p=0.005)$. In response to $1 \mathrm{~s}$ current steps between 5 and $25 \mathrm{pA}$, linopirdine induced an increase in firing frequency at each current step tested (Fig. $7 D, E)(n=8$; $p<0.05)$. When 15 and $20 \mathrm{pA}$ current step amplitudes were introduced, linopirdine induced robust increases in firing frequency by $10.6 \pm 2.6 \mathrm{~Hz}(n=8 ; p=0.005)$ and $10.8 \pm 2.7 \mathrm{~Hz}$ $(n=8 ; p=0.005)$, respectively. However, at $25 \mathrm{pA}$, the linopirdine-induced increase in frequency was smaller $(7.6 \pm 3.2$ $\mathrm{Hz} ; n=8 ; p=0.045)$, suggesting that linopirdine effects narrowed as the cell approached maximum firing frequency. We saw no indication that linopirdine altered AP repolarization, providing additional confirmation that linopirdine does not block Kv3 channels. Finally, as an independent means of assessing the effect of $I_{\mathrm{M}}$ on interneuronal excitability, we applied the Kv7 channel opener retigabine $(10 \mu \mathrm{M})$. In seven of seven neurons, retigabine caused a cessation of spontaneous firing (Fig. $7 F$ ), hyperpolarized the cells from $-53.6 \pm 2.7$ to $-58.8 \pm 1.4 \mathrm{mV}(n=7 ; p=$ 0.027 ), and greatly shunted depolarization-induced firing (Fig. $7 G, H)$.

Therefore, $I_{\mathrm{M}}$ appeared to primarily control the ISI and was 


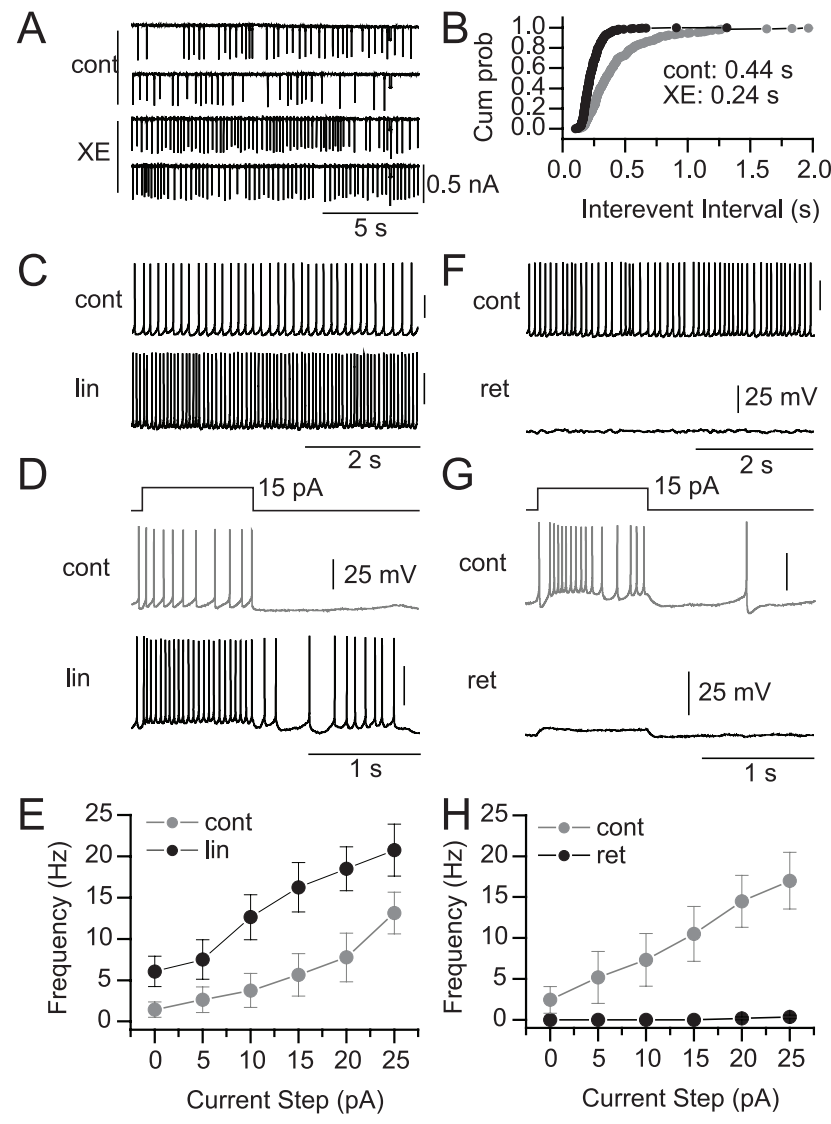

Figure 7. Effects of $I_{M}$ antagonists on AP firing pattern. Loose-patch recording $(\boldsymbol{A})$ and corresponding cumulative probability plot (Cum prob; $\boldsymbol{B}$ ) of action current intervals before (cont) or after (XE) application of $8 \mu \mathrm{M}$ XE-991. Square current steps near the end of traces in $\boldsymbol{A}$ indicate $-1 \mathrm{mV}, 100 \mathrm{~ms}$ duration seal tests. Spontaneous AP firing $(\boldsymbol{C})$ and response $(\boldsymbol{D})$ to a $1 \mathrm{~s}, 15 \mathrm{pA}$ current step from the resting potential under control conditions (cont) (gray) and in the presence of $20 \mu \mathrm{m}$ linopirdine (lin) (black). $\boldsymbol{E}$, Plot of current step amplitude versus AP frequency across a $0-25 \mathrm{pA}$ range for control (gray) and $20 \mu \mathrm{m}$ linopirdine (black) conditions ( $p<0.05$; $n=8)$. Spontaneous AP firing $(\boldsymbol{F})$ and response $(\boldsymbol{G})$ to a $1 \mathrm{~s}, 15 \mathrm{pA}$ current step from the resting potential under control conditions (cont) (gray) and in the presence of $10 \mu \mathrm{m}$ retigabine (ret) (black). $\boldsymbol{H}$, Plot of current step amplitude versus AP frequency across a $0-25 \mathrm{pA} \mathrm{range} \mathrm{for} \mathrm{control}$ (cont) (gray) and $10 \mu \mathrm{m}$ retigabine (ret) (black) conditions $(p<0.05 ; n=7)$.

particularly effective in influencing firing frequency in response to small depolarizing current steps near the resting potential.

\section{Somatodendritic localization of Kv7 channels best reproduced $I_{\mathrm{M}}$-mediated outward currents}

To understand how the presence and localization of $I_{\mathrm{M}}$ influenced interneuron properties, we turned to multicompartment models of interneurons. Because O-LM cells were the most abundant $I_{\mathrm{M}}$-containing $\mathrm{SO}$ cell type, we chose to model two O-LM cells (Fig. 4, cells 1-2) in which $I_{\mathrm{M}}$ had been pharmacologically detected. In construction of the model, Kv7 channels were localized to different cellular regions: soma only, soma and all dendrites, soma and primary dendrites, and axon only (Fig. 8A-D). Primary dendrites are defined here as dendrites that originate from the soma and extend to the first branch point.

For each $I_{\mathrm{M}}$ distribution, the conductance density was adjusted to generate $\sim 1 \mathrm{nA}$ of outward current after voltage command to +40 from $-60 \mathrm{mV}$, a value close to that measured in our whole-cell recordings. The density obtained was different for each of the four $I_{M}$ distributions explored (Table 1). Values ranged from $0.12 \mathrm{pS} / \mu \mathrm{m}^{2}$ for the somatodendritic distribution to $6.40 \mathrm{pS} / \mu \mathrm{m}^{2}$ for the soma only distribution. Interestingly, our predicted density for the soma only distribution of $I_{\mathrm{M}}$ (5.65-6.4 $\mathrm{pS} / \mu \mathrm{m}^{2}$ ) is very similar to the density used by Hu et al. (2002) in which they included only somatic $I_{\mathrm{M}}\left(6.7 \mathrm{pS} / \mu \mathrm{m}^{2}\right)$. For the distribution in which $I_{\mathrm{M}}$ was limited to the axon only, conductance levels required to generate a $\sim 1 \mathrm{nA}$ somatic current were $\sim 280$ $1200 \mathrm{pS} / \mu \mathrm{m}^{2}, \sim 50-190$ times larger than the density needed in the soma alone and 1600-2300 times larger than needed for somatodendritic distributions. Moreover, the high axonal Kv7 channel density made $I_{\mathrm{M}}$ the dominant repolarizing conductance shaping AP half-width, which greatly abbreviated the AP amplitude, ceased spontaneous firing, and, unlike that measured experimentally (Martina et al., 2000), no longer permitted AP initiation in the axon-bearing dendrite. When $I_{\mathrm{M}}$ density was set to $0.75 \mathrm{pS} / \mu \mathrm{m}^{2}$ for the four distributions, somatodendritic $I_{\mathrm{M}}$ was the largest (Fig. $8 A-D$, insets), with the other distributions generating less somatic current (Fig. $8 E$ ).

An independent estimate of the $I_{\mathrm{M}}$ density was obtained using experimental measurements of the capacitance transient, which can be used to determine the approximate surface area that is sampled by the somatic recording electrode. In stepping from -60 to $-65 \mathrm{mV}$ under whole-cell VC conditions, the capacitance transient was generated in the same cells that were modeled (Fig. $8 \mathrm{~F}$, inset) (cell 1, $38.0 \mathrm{pF}$; cell 2, $32.4 \mathrm{pF}$ ). Assuming a specific membrane capacitance of $0.9 \mu \mathrm{F} / \mathrm{cm}^{2}$ and $E_{K}$ of $-95 \mathrm{mV}$, the density required to generate $1 \mathrm{nA}$ of outward current is as follows:

$$
\begin{gathered}
\text { surface area }=\frac{38.0 \mathrm{pF}}{0.009 \mathrm{pF} / \mu \mathrm{m}^{2}}=4222 \mu \mathrm{m}^{2} \\
\text { conductance }=\frac{1 \mathrm{nA}}{121.2 \mathrm{mV}}=8.25 \mathrm{nS} \\
\text { density }=\frac{8.25 \mathrm{nS}}{4222 \mu \mathrm{m}^{2}}=1.95 \mathrm{pS} / \mu \mathrm{m}^{2} .
\end{gathered}
$$

A similar calculation for cell 2 yields a density of $2.29 \mathrm{pS} / \mu \mathrm{m}^{2}$. These density values lie between those predicted for $I_{\mathrm{M}}$ distributed somatodendritically and $I_{\mathrm{M}}$ distributed in the soma and primary dendrites only (Table 1 ). This calculated distribution also corresponds well with the immunocytochemical localization of Kv7.2 and 7.3 subunits to the soma and dendrites (Fig. 1).

\section{Simulation of $I_{M}$ inhibition and enhancement in O-LM interneuron models}

Having estimated $I_{\mathrm{M}}$ density and compartmental localization to somatodendritic regions ( $I_{\mathrm{M}}$ distributed in the soma and all dendrites was used for all subsequent simulations), we then proceeded to determine the influence of $I_{\mathrm{M}}$ on firing properties in O-LM interneuron models using VC and CC protocols similar to the experimental conditions in Figures 2 and 7. Making $g_{M}$ equal to zero, which simulated the XE-991 case ("XE"), increased spontaneous firing (Fig. 9 $A_{2}$ ) compared with control conditions (Fig. $\left.9 A_{1}\right)$. Simulating the action of the Kv7 channel opener retigabine ["ret" (Wickenden et al., 2000)] arrested spontaneous firing (Fig. $\left.9 A_{3}\right)$, similar to experimental observations. In response to a $1 \mathrm{~s}$ long, 15 pA current step, the XE condition increased AP frequency without changing AP half-width $\left(\right.$ Fig. $\left.9 B_{2}, E\right)$, whereas the ret condition shunted AP firing (Fig. $9 B_{3}, E$ ) compared with control conditions (Fig. $9 B_{1}, E$ ). Interestingly, after introduction of a 
$5 \mathrm{~Hz}$ sinusoidal current, the model exhibited an increase in AP reliability (Fig. $9 C_{1}, C_{2}$ ) compared with that seen in O-LM cells after $\mathrm{mAChR}$ activation (Lawrence et al., 2006). After simulating the effects of XE-991 (Fig. 9D, red) or retigabine (Fig. $9 D$, blue) in VC, the model also reproduced the shifts in $I_{\text {hold }}$ and changes $I_{\mathrm{M}}$ amplitude apparent (Fig. 9D). Finally, as observed in experimental conditions, the effects of $I_{\mathrm{M}}$ inhibition or enhancement on firing diminished as the model approached maximal firing frequencies (Fig. $9 F)$, suggesting that $I_{\mathrm{M}}$ is most effective in modulating firing frequency at low or moderate current steps. Thus, inhibition or enhancement of somatodendritic $I_{M}$ in O-LM cell models reproduces salient aspects of $I_{\mathrm{M}}$-related effects observed experimentally.

\section{The role of $g_{M}$ in shaping interneuronal AHP and interspike interval}

Under what conditions can interneuronal $g_{\mathrm{M}}$ be activated? In hippocampal pyramidal cells, after eliciting multiple APs, $I_{M}$ mediates a mAHP (Storm, 1990; Gu et al., 2005). Interestingly, $I_{M}$ mediates the mAHP even after a single AP (Gu et al., 2005), which was only reproduced when $I_{\mathrm{M}}$ was modeled to have rapid activation kinetics at voltages more positive than $-20 \mathrm{mV}$ (Gu et al., 2005). Having experimentally confirmed that $I_{\mathrm{M}}$ activates rapidly in SO interneurons (Fig. 5D), we investigated conditions under which $g_{\mathrm{M}}$ is activated in the O-LM model (Fig. 10). After activation by a single AP (Fig. $10 A), g_{\mathrm{M}}$ reached maximal activation $(\sim 40 \%)$ during AP repolarization (Fig. $10 A_{i i}$ ). Despite this strong activation, $I_{\mathrm{M}}$ plays a negligible role in AP repolarization, because $g_{\mathrm{Kdrf}}$ and $g_{\mathrm{K}(\mathrm{Ca})}$ are the dominant $\mathrm{K}^{+}$conductances (Fig. $10 A_{i i i}$ ), with $I_{\mathrm{M}}$ contributing only $6 \%$ to the total active $\mathrm{K}^{+}$conductance during repolarization (Fig. $10 A_{i v}$ ). As $g_{\mathrm{Kdrf}}$ and $g_{\mathrm{K}(\mathrm{Ca})}$ rapidly decay after the $\mathrm{AP}, g_{\mathrm{M}}$ remains active for several hundreds of milliseconds (Fig. $10 A_{i i i}$ ) so that $g_{\mathrm{M}}$ becomes the major conductance during the ISI (Fig. $10 A_{i v}$ ). These observations explain not only how $g_{M}$ can influence the AHP and spontaneous firing but also why $g_{\mathrm{M}}$ contributes so little to shaping the AP waveform (Fig. $10 B_{i-i i i}$ ). The model also accounts, in part, for how $g_{M}$ can influence the ISI yet, paradoxically, have little effect on the amplitude of the AHP after a $1 \mathrm{~s}$ train of APs (Fig. 10C,D) (Lawrence et al., 2006a). When $g_{M}$ is inhibited, the accompanying increase in AP frequency (Fig. $10 C_{i i}$ ) results in an enhanced accumulation of $g_{\mathrm{K}(\mathrm{Ca})}$ (Fig. $10 D_{i i, i i i}$ ), which can obscure a reduction in AHP mediated by $g_{\mathrm{M}}$ inhibition (Fig. $10 D_{i}$ ). Finally, the model is also consistent with published work (Lawrence et al., 2006a), indicating that linopirdine does not change the first spike latency when the cell is depolarized from $-60 \mathrm{mV}$. At this voltage, $I_{\mathrm{M}}$ is active by only $0.12 \%$, contributing very little to $R_{\mathrm{m}}$ or $\tau_{\mathrm{m}}$. Overall, $g_{\mathrm{M}}$ appears to be strongly recruited by APs but does not contribute to shaping excitability until the ISI, when faster deactivating conductances that shape the AP waveform no longer dominate.

\begin{tabular}{|c|c|c|}
\hline & $\begin{array}{l}\text { Conductance density } \\
\left(\mathrm{pS} / \mu \mathrm{m}^{2}\right)\end{array}$ & $\begin{array}{l}\text { Conductance density } \\
\left(\mathrm{pS} / \mu \mathrm{m}^{2}\right)\end{array}$ \\
\hline$I_{M}$ distribution & Cell 1 & Cell 2 \\
\hline Soma & 6.40 & 5.65 \\
\hline Soma and all dendrites & 0.75 & 0.12 \\
\hline Soma and primary dendrites & 3.00 & 2.57 \\
\hline Axon & 1200 & 280 \\
\hline Calculation from experiments & 1.95 & 2.29 \\
\hline
\end{tabular}

\section{Discussion}

Interneuronal Kv7 channels are localized somatodendritically In this paper, we present immunocytochemical, electrophysiological, and computational evidence that converges on the conclusion that a population of Kv7 channels is localized somatodendritically in O-LM cells. As evidenced by Kv7.2 immunocytochemistry and susceptibility to block by $0.5 \mathrm{~mm}$ TEA, the molecular identity of $I_{\mathrm{M}}$ on SO interneurons is most likely to be Kv7.2/Kv7.3 heteromers (Shah et al., 2002). Although we do not know to what extent Kv7.5 may be expressed in SO interneurons, strong Kv7.5 expression is expected to confer a lower degree of TEA sensitivity (Schroeder et al., 2000). Although both immunocytochemical and electrophysiological data indicate considerable heterogeneity in the expression of Kv7 channels, the relationship between immunocytochemical detection of Kv7 subunits and $I_{\mathrm{M}}$ amplitude is likely to be complex, involving not only practical limits in the detection threshold for each these parameters but probably also other parameters such as channel open probability, 


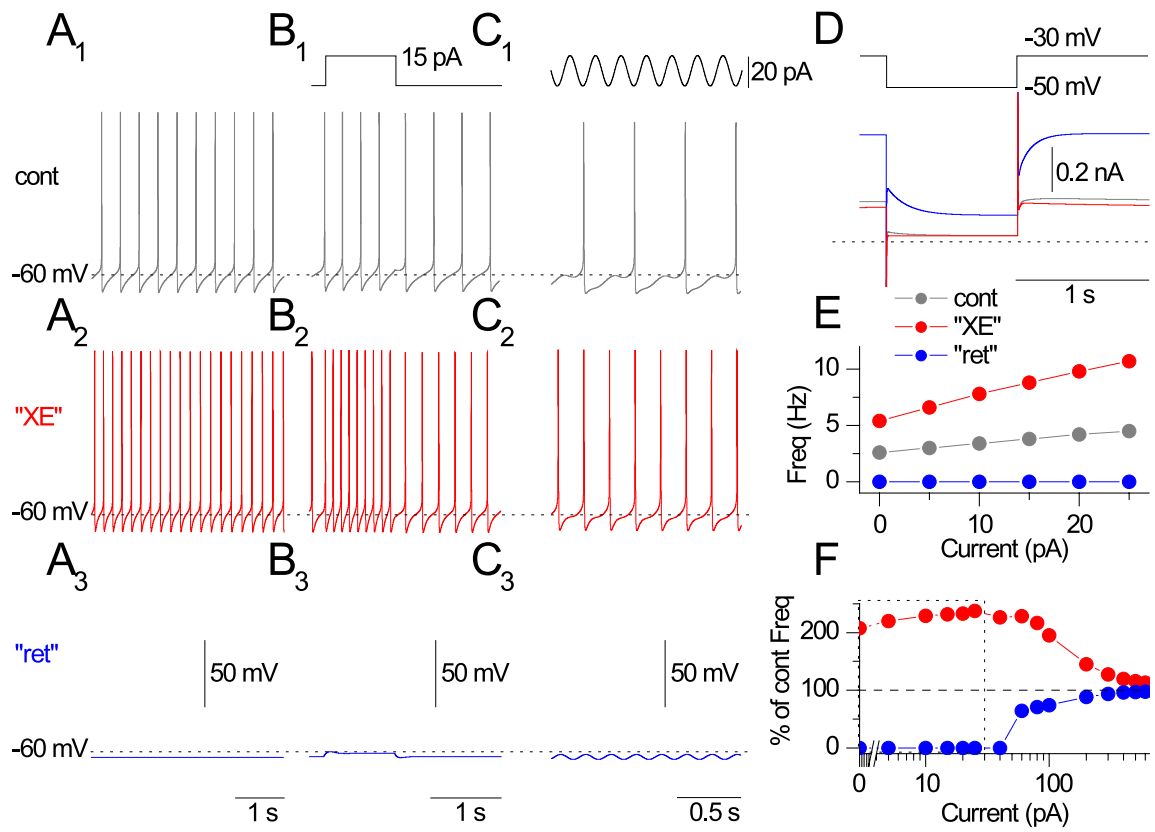

Figure 9. Simulation of $I_{M}$ inhibition and augmentation in 0-LM interneuron model. Simulations were performed on cell 1 with a somatodendritic $I_{\mathrm{M}}$ distribution. $A$, Spontaneous firing simulating in control $\left(A_{1}\right), \mathrm{XE}-991\left(A_{2}\right)$, and retigabine $\left(A_{3}\right)$ conditions. $B$, Introduction of 1 s long, $15 \mathrm{pA}$ step into the soma for control $\left(\boldsymbol{B}_{1}\right), \mathbf{X E}\left(\boldsymbol{B}_{2}\right)$, and retigabine $\left(\boldsymbol{B}_{3}\right)$. $\boldsymbol{C}$, Sinusoidal current $(20 \mathrm{pA})$ at 5 $\mathrm{Hz}$ introduced into the soma for control $\left(\boldsymbol{C}_{7}\right), \mathrm{XE}\left(\boldsymbol{C}_{2}\right)$, and retigabine $\left(\boldsymbol{C}_{3}\right) . \boldsymbol{D}$, In VC, a step was applied from -30 to $-50 \mathrm{mV}$ for control (gray), $X E$ (red), and retigabine (blue). $E$, AP frequency in response to $0-25 \mathrm{pA}$ current pulses from the resting potential for control (cont; gray), XE (red), and retigabine (ret; blue) conditions. $F$, Plot of AP frequency, as a percentage of control frequency, for XE (red) and retigabine (blue) conditions across a wide range of current steps. Note that the effects of XE and retigabine on firing frequency diminish with increasing current step amplitude. The dotted box indicates the range of current step values shared with $\boldsymbol{E}$.

$\mathrm{PIP}_{2}$ (phosphatidylinositol 4,5-bisphosphate) level, dendritic geometry, and the level of tonic mAChR-mediated inhibition. However, as implied by the observation that retigabine had a detectable effect in all recordings, it is possible that all SO interneurons express Kv7 channels to some extent.

To explore how the localization of $\mathrm{Kv} 7$ channels influenced the detection of somatically recorded $I_{\mathrm{M}}$, we used realistic multicompartment models in which Kv7 channels were localized to different regions of the soma, dendrites, or axon. Our results indicate that $I_{\mathrm{M}}$ characteristics obtained with whole-cell recordings point to a somatodendritic localization. Although we cannot rule out that interneuron axons also possess Kv7 channels, our results argue that axonal channels are unlikely to fully account for $I_{\mathrm{M}}$ measured somatically because of the poor space clamp on the axon and the unrealistically high axonal densities required to generate the magnitude of $I_{\mathrm{M}}$ seen experimentally. Indeed, in comparing the capacitance of the cell estimated experimentally at the soma with the total capacitance in the O-LM model, it is likely that voltage control is limited to a $\sim 100 \mu \mathrm{M}$ region surrounding the soma (Fig. $8 F$ ), which corresponds well with the cellular location where immunoreactivity for $\mathrm{Kv} 7$ channels is strongest (Fig. 1). Finally, modulating somatodendritic $I_{M}$ in the model (Fig. 9) recapitulates the effects of linopirdine and retigabine on AP firing measured experimentally (Fig. 7). Thus, our electrophysiological results are most likely explained by somatodendritically localized Kv7 channels.

\section{Kv7 channels are specialized to control ISI in SO interneurons}

In hippocampal pyramidal cells, $I_{\mathrm{M}}$ is well known for its role in spike frequency accommodation and has therefore been associ- ated with neurons that exhibit strong spike frequency accommodation. Given that O-LM interneurons exhibit only modest spike frequency accommodation (Lien et al., 2002; Lawrence et al., 2006a), the discovery of $I_{\mathrm{M}}$ in O-LM cells may be somewhat surprising. Moreover, the overlap in TEA sensitivity between $I_{M}$ and Kv3-like delayed rectifier channels may be an additional reason that it has not been appreciated in nucleated patches from SO cells before this study (Lien et al., 2002). Interestingly, in five of six nucleated patches from SO cells, we did detect a change in $I_{\text {hold }}$ at $-30 \mathrm{mV}(-1.8 \pm 0.3 \mathrm{pA}$; $n=5 ; p=0.008)$ after 3 min wash-in of 4 $\mu \mathrm{M}$ XE-991, a value comparable with the magnitude of change in $I_{\text {hold }}$ predicted in a nucleated patch model using our obtained estimate of $I_{M}$ density (data not shown). What function might $I_{M}$ have in O-LM cells, and how does $I_{M}$ differ from that of other $\mathrm{K}^{+}$currents in O-LM cells? In this paper, we show that although Kv3 and Kv7 channels are both activated by similar depolarizing stimuli, the two channel types play fundamentally different roles in the regulation of interneuronal excitability because of their different time courses of activation (Fig. 5D) and deactivation (Figs. 2, 6G,H). Kv3 channels are strongly activated by the $\mathrm{AP}$, comprising the dominant conductance mediating repolarization of the AP. The rapid activation and deactivation kinetics of Kv3 channels enables rapid and precise repolarization of the AP and endows interneurons with the capacity to fire APs at high frequencies (Atzori et al., 2000; Rudy and McBain, 2001; Lien et al., 2002); indeed, introducing a Kv3-like conductance into a pyramidal cell transforms it to a fast spiking phenotype (Lien and Jonas, 2003). Neuromodulation of Kv3 channels changes spike width (Atzori et al., 2000), which may influence downstream synaptic transmission by impacting calcium entry during the spike (Goldberg et al., 2005). Kv3 channels also ensure that sodium channels undergo sufficient recovery from inactivation, thus setting the upper limit on firing frequency (Atzori et al., 2000; Rudy and McBain, 2001). In contrast, Kv7 channels activate during the AP but do not influence spike width or AP repolarization, primarily because they comprise a minor conductance during AP repolarization. However, $I_{M}$ becomes a dominant conductance relative to Kv3-mediated conductances during the ISI. The ability of $I_{\mathrm{M}}$ to influence AP frequency without influencing AP half-width may be a mechanism by which SO interneurons can tune ISI while preserving the fidelity of calcium entry that might occur during the AP. $I_{\mathrm{M}}$ inhibition also has consequences on other conductances, but it is interesting that cholinergic signaling mechanisms in O-LM cells appear to have evolved to repress a $\mathrm{Ca}^{2+}$-dependent $\mathrm{K}^{+}$conductance after $\mathrm{mAChR}$ activation (Lawrence et al., 2006a) that would otherwise probably be enhanced by $I_{\mathrm{M}}$ inhibition (Fig. $10 \mathrm{D}$ ).

Interneuronal $I_{\mathrm{M}}$ may also be important in the broader context of cellular and network oscillations (Cooper et al., 2001). In CA1 pyramidal cells, $I_{\mathrm{M}}$ and $I_{\mathrm{h}}$ mediate a subthreshold theta resonance (Hu et al., 2002). A theta resonance has been identified in 
SO interneurons that is similar to that of pyramidal cells (Pike et al., 2000). The potential contribution of $I_{\mathrm{M}}$ and $I_{\mathrm{h}}$ to theta resonance, coupled to their depolarized resting potential relative to pyramidal cells (Gloveli et al., 2005; Lawrence et al., 2006a), tendency to fire spontaneously (McBain et al., 1994; Maccaferri and McBain, 1996), relatively high $R_{\mathrm{m}}$ (Gloveli et al., 2005; Lawrence et al., 2006a), intrinsic spike frequency preference (Pike et al., 2000; Lawrence et al., 2006a), and susceptibility to entrainment by GABAergic afferents of the medial septum (Toth et al., 1997), not only put additional constraints on the range of ISIs available to SO interneurons but also offers mechanisms by which ISI can be tuned through extrinsic neuromodulation. Interestingly, $\mathrm{mAChR}$ modulation in O-LM cells, which is associated with $I_{\mathrm{M}}$ inhibition (Lawrence et al., 2006a), appears to amplify theta rhythmicity by enhancing AP reliability to theta frequency oscillatory input (Lawrence et al., 2006b), a finding that is reproduced in our O-LM model (Fig. 9C). Thus, neuromodulation of somatodendritic $I_{\mathrm{M}}$ and $I_{\mathrm{h}}$ in $\mathrm{SO}$ interneurons may be mechanisms by which ISI can be tuned to alter the degree of engagement of SO interneurons in network activity.

\section{Pathophysiological implications of $I_{M}$ in hippocampal interneurons}

Recently, the Kv7 channels have been shown to factor prominently into inherited human epilepsies. Benign familial neonatal convulsions, a type of epilepsy involving genetic mutations of Kv7.2/Kv7.3 channels, result in epileptic activity early in development (Jentsch, 2000). Linopirdine also induces epileptic activity in hippocampal slices in 1- to 2-weekold animals (Pena and Alavez-Perez, 2006). In experimental models in which Kv7.2 channels are globally suppressed, CA1 pyramidal cells exhibit hyperexcitability and reduced $I_{\mathrm{M}}$ (Peters et al., 2005; Otto et al., 2006). However, an interneuronal component of reduced expression of somatodendritic Kv7.2 channels to changes in network excitability has not been addressed. At first glance, increased release of GABA resulting from reduced expression of interneuron Kv7.2 channels might be expected to ameliorate or reduce seizure susceptibility. However, GABA is excitatory early in development; seizure susceptibility is actually increased by GABA and reduced by $\mathrm{GABA}_{\mathrm{A}}$ antagonists (Khazipov et al., 2004). Thus, it is possible that suppression of $I_{M}$ in interneurons could exacerbate epileptogenic activity through enhanced GABAergic transmission (Cossart et al., 2005).

Conversely, $I_{\mathrm{M}}$ channel openers such as retigabine are steadily gaining recognition for their advantageous antiepileptic properties (Rogawski, 2006). Although retigabine has been described as a "GABA enhancer" (Czuczwar and Patsalos, 2001) for its action at postsynaptic $\mathrm{GABA}_{\mathrm{A}}$ receptors (Otto et al., 2002), our observation that retigabine effectively arrests spontaneous firing of interneurons (Fig. 7) predicts that retigabine may impair AP driven GABAergic transmission to some extent. Although it is unexpected that the actions of an antiepileptic agent would in- clude a reduction in GABAergic transmission, reducing excitability of both pyramidal cells and interneurons may be more effective in disrupting pathological network synchrony than reducing excitability of pyramidal cells alone. Thus, the antiepileptic action of retigabine might be reinterpreted as antimuscarinic in nature, effectively counteracting the action of acetylcholine in promoting rhythmicity of the hippocampal network via modulation of $I_{\mathrm{M}}$ in pyramidal cells and interneurons (Cobb and Davies, 2005; Lawrence et al., 2006b).

In summary, our immunocytochemical, electrophysiological, and modeling evidence converges on the conclusion that most $I_{\mathrm{M}}$ detected somatically in SO interneurons is attributable to somatodendritically activated $I_{\mathrm{M}}$. The activation of somatodendritic $I_{\mathrm{M}}$ has a major influence on the control of ISI. Modulation of $I_{\mathrm{M}}$ has potent effects on interneuronal excitability, a novel means of influencing the excitability of the hippocampal network.

\section{References}

Atzori M, Lau D, Tansey EP, Chow A, Ozaita A, Rudy B, McBain CJ (2000) $\mathrm{H} 2$ histamine receptor-phosphorylation of Kv3.2 modulates interneuron fast spiking. Nat Neurosci 3:791-798.

Buzsaki G (2002) Theta oscillations in the hippocampus. Neuron 33:325-340.

Chung HJ, Jan YN, Jan LY (2006) Polarized axonal surface expression of neuronal KCNQ channels is mediated by multiple signals in the KCNQ2 and KCNQ3 C-terminal domains. Proc Natl Acad Sci USA 103:8870-8875.

Clements JD, Bekkers JM (1997) Detection of spontaneous synaptic events with an optimally scaled template. Biophys J 73:220-229. 
Cobb SR, Davies CH (2005) Cholinergic modulation of hippocampal cells and circuits. J Physiol (Lond) 562:81-88.

Cooper EC, Jan LY (2003) M-channels: neurological diseases, neuromodulation, and drug development. Arch Neurol 60:496-500.

Cooper EC, Aldape KD, Abosch A, Barbaro NM, Berger MS, Peacock WS, Jan YN, Jan LY (2000) Colocalization and coassembly of two human brain M-type potassium channel subunits that are mutated in epilepsy. Proc Natl Acad Sci USA 97:4914-4919.

Cooper EC, Harrington E, Jan YN, Jan LY (2001) M channel KCNQ2 subunits are localized to key sites for control of neuronal network oscillations and synchronization in mouse brain. J Neurosci 21:9529-9540.

Cossart R, Bernard C, Ben-Ari Y (2005) Multiple facets of GABAergic neurons and synapses: multiple fates of GABA signalling in epilepsies. Trends Neurosci 28:108-115.

Czuczwar SJ, Patsalos PN (2001) The new generation of GABA enhancers. Potential in the treatment of epilepsy. CNS Drugs 15:339-350.

Delmas P, Brown DA (2005) Pathways modulating neural KCNQ/M (Kv7) potassium channels. Nat Rev Neurosci 6:850-862.

Destexhe A, Neubig M, Ulrich D, Huguenard J (1998) Dendritic lowthreshold calcium currents in thalamic relay cells. J Neurosci 18:3574-3588.

Devaux JJ, Kleopa KA, Cooper EC, Scherer SS (2004) KCNQ2 is a nodal $\mathrm{K}^{+}$ channel. J Neurosci 24:1236-1244.

Gentet LJ, Stuart GJ, Clements JD (2000) Direct measurement of specific membrane capacitance in neurons. Biophys J 79:314-320.

Gloveli T, Dugladze T, Saha S, Monyer H, Heinemann U, Traub RD, Whittington MA, Buhl EH (2005) Differential involvement of oriens/pyramidale interneurones in hippocampal network oscillations in vitro. J Physiol (Lond) 562:131-147.

Goldberg EM, Watanabe S, Chang SY, Joho RH, Huang ZJ, Leonard CS, Rudy B (2005) Specific functions of synaptically localized potassium channels in synaptic transmission at the neocortical GABAergic fast-spiking cell synapse. J Neurosci 25:5230-5235.

Gu N, Vervaeke K, Hu H, Storm JF (2005) Kv7/KCNQ/M and HCN/h, but not KCa2/SK channels, contribute to the somatic medium afterhyperpolarization and excitability control in CAl hippocampal pyramidal cells. J Physiol (Lond) 566:689-715.

Hadley JK, Noda M, Selyanko AA, Wood IC, Abogadie FC, Brown DA (2000) Differential tetraethylammonium sensitivity of KCNQ1-4 potassium channels. Br J Pharmacol 129:413-415.

Hadley JK, Passmore GM, Tatulian L, Al-Qatari M, Ye F, Wickenden AD, Brown DA (2003) Stoichiometry of expressed KCNQ2/KCNQ3 potassium channels and subunit composition of native ganglionic $\mathrm{M}$ channels deduced from block by tetraethylammonium. J Neurosci 23:5012-5019.

Halliwell JV, Adams PR (1982) Voltage-clamp analysis of muscarinic excitation in hippocampal neurons. Brain Res 250:71-92.

Hu H, Vervaeke K, Storm JF (2002) Two forms of electrical resonance at theta frequencies, generated by $\mathrm{M}$-current, $\mathrm{h}$-current and persistent $\mathrm{Na}^{+}$ current in rat hippocampal pyramidal cells. J Physiol (Lond) 545:783-805.

Jentsch TJ (2000) Neuronal KCNQ potassium channels: physiology and role in disease. Nat Rev Neurosci 1:21-30.

Jow F, Wang K (2000) Cloning and functional expression of rKCNQ2 K(+) channel from rat brain. Brain Res Mol Brain Res 80:269-278.

Khazipov R, Khalilov I, Tyzio R, Morozova E, Ben-Ari Y, Holmes GL (2004) Developmental changes in GABAergic actions and seizure susceptibility in the rat hippocampus. Eur J Neurosci 19:590-600.

Lamas JA, Selyanko AA, Brown DA (1997) Effects of a cognition-enhancer, linopirdine (DuP 996), on M-type potassium currents (IK(M)) and some other voltage- and ligand-gated membrane currents in rat sympathetic neurons. Eur J Neurosci 9:605-616.

Lawrence JJ, Statland JM, Grinspan ZM, McBain CJ (2006a) Cell typespecific dependence of muscarinic signalling in mouse hippocampal stratum oriens interneurones. J Physiol (Lond) 570:595-610.

Lawrence JJ, Grinspan ZM, Statland JM, McBain CJ (2006b) Muscarinic receptor activation tunes mouse stratum oriens interneurons to amplify spike reliability. J Physiol (Lond) 571:555-562.

Lien CC, Jonas P (2003) Kv3 potassium conductance is necessary and kinetically optimized for high-frequency action potential generation in hippocampal interneurons. J Neurosci 23:2058-2068.

Lien CC, Martina M, Schultz JH, Ehmke H, Jonas P (2002) Gating, modulation and subunit composition of voltage-gated $\mathrm{K}(+)$ channels in den- dritic inhibitory interneurones of rat hippocampus. J Physiol (Lond) 538:405-419.

Maccaferri G (2005) Stratum oriens horizontal interneurone diversity and hippocampal network dynamics. J Physiol (Lond) 562:73-80.

Maccaferri G, Lacaille JC (2003) Interneuron diversity series: hippocampal interneuron classifications-making things as simple as possible, not simpler. Trends Neurosci 26:564-571.

Maccaferri G, McBain CJ (1996) The hyperpolarization-activated current (Ih) and its contribution to pacemaker activity in rat CAl hippocampal stratum oriens-alveus interneurones. J Physiol (Lond) 497:119-130.

Magee JC (1998) Dendritic hyperpolarization-activated currents modify the integrative properties of hippocampal CAl pyramidal neurons. J Neurosci 18:7613-7624.

Martina M, Schultz JH, Ehmke H, Monyer H, Jonas P (1998) Functional and molecular differences between voltage-gated $\mathrm{K}^{+}$channels of fastspiking interneurons and pyramidal neurons of rat hippocampus. J Neurosci 18:8111-8125.

Martina M, Vida I, Jonas P (2000) Distal initiation and active propagation of action potentials in interneuron dendrites. Science 287:295-300.

McBain CJ, DiChiara TJ, Kauer JA (1994) Activation of metabotropic glutamate receptors differentially affects two classes of hippocampal interneurons and potentiates excitatory synaptic transmission. J Neurosci 14:4433-4445.

McQuiston AR, Madison DV (1999) Muscarinic receptor activity induces an afterdepolarization in a subpopulation of hippocampal CA1 interneurons. J Neurosci 19:5703-5710.

Migliore M, Cook EP, Jaffe DB, Turner DA, Johnston D (1995) Computer simulations of morphologically reconstructed CA3 hippocampal neurons. J Neurophysiol 73:1157-1168.

Nunemaker CS, DeFazio RA, Moenter SM (2003) A targeted extracellular approach for recording long-term firing patterns of excitable cells: a practical guide. Biol Proced Online 5:53-62.

Oliva Jr AA, Jiang M, Lam T, Smith KL, Swann JW (2000) Novel hippocampal interneuronal subtypes identified using transgenic mice that express green fluorescent protein in GABAergic interneurons. J Neurosci 20:3354-3368.

Otto JF, Kimball MM, Wilcox KS (2002) Effects of the anticonvulsant retigabine on cultured cortical neurons: changes in electroresponsive properties and synaptic transmission. Mol Pharmacol 61:921-927.

Otto JF, Yang Y, Frankel WN, White HS, Wilcox KS (2006) A spontaneous mutation involving Kcnq2 (Kv7.2) reduces M-current density and spike frequency adaptation in mouse CA1 neurons. J Neurosci 26:2053-2059.

Pan Z, Kao T, Horvath Z, Lemos J, Sul J-Y, Cranstoun SD, Bennett V, Scherer SS, Cooper EC (2006) A common ankyrin-G-based mechanism retains KCNQ and NaV channels at electrically active domains of the axon. J Neurosci 26:2599-2613.

Parra P, Gulyas AI, Miles R (1998) How many subtypes of inhibitory cells in the hippocampus? Neuron 20:983-993.

Pena F, Alavez-Perez N (2006) Epileptiform activity induced by pharmacologic reduction of M-current in the developing hippocampus in vitro. Epilepsia 47:47-54.

Peters HC, Hu H, Pongs O, Storm JF, Isbrandt D (2005) Conditional transgenic suppression of $\mathrm{M}$ channels in mouse brain reveals functions in neuronal excitability, resonance and behavior. Nat Neurosci 8:51-60.

Pike FG, Goddard RS, Suckling JM, Ganter P, Kasthuri N, Paulsen O (2000) Distinct frequency preferences of different types of rat hippocampal neurones in response to oscillatory input currents. J Physiol (Lond) 529:205-213.

Pouille F, Scanziani M (2004) Routing of spike series by dynamic circuits in the hippocampus. Nature 429:717-723.

Prole DL, Lima PA, Marrion NV (2003) Mechanisms underlying modulation of neuronal KCNQ2/KCNQ3 potassium channels by extracellular protons. J Gen Physiol 122:775-793.

Rogawski MA (2006) Diverse mechanisms of antiepileptic drugs in the development pipeline. Epilepsy Res 69:273-294.

Rudy B, McBain CJ (2001) Kv3 channels: voltage-gated K+ channels designed for high-frequency repetitive firing. Trends Neurosci 24:517-526.

Saraga F, Wu CP, Zhang L, Skinner FK (2003) Active dendrites and spike propagation in multi-compartment models of oriens-lacunosum/moleculare hippocampal interneurons. J Physiol (Lond) 552:673-689.

Schnee ME, Brown BS (1998) Selectivity of linopirdine (DuP 996), a neuro- 
transmitter release enhancer, in blocking voltage-dependent and calcium-activated potassium currents in hippocampal neurons. J Pharmacol Exp Ther 286:709-717.

Schroeder BC, Hechenberger M, Weinreich F, Kubisch C, Jentsch TJ (2000) KCNQ5, a novel potassium channel broadly expressed in brain, mediates M-type currents. J Biol Chem 275:24089-24095.

Selyanko AA, Brown DA (1999) M-channel gating and simulation. Biophys J 77:701-713.

Shah MM, Mistry M, Marsh SJ, Brown DA, Delmas P (2002) Molecular correlates of the M-current in cultured rat hippocampal neurons. J Physiol (Lond) 544:29-37.

Somogyi P, Klausberger T (2005) Defined types of cortical interneurone structure space and spike timing in the hippocampus. J Physiol (Lond) $562: 9-26$.

Storm JF (1990) Potassium currents in hippocampal pyramidal cells. Prog Brain Res 83:161-187.

Suh BC, Hille B (2002) Recovery from muscarinic modulation of M current channels requires phosphatidylinositol 4,5-bisphosphate synthesis. Neuron 35:507-520.

Toth K, Freund TF, Miles R (1997) Disinhibition of rat hippocampal pyra- midal cells by GABAergic afferents from the septum. J Physiol (Lond) 500:463-474.

Wang HS, Pan Z, Shi W, Brown BS, Wymore RS, Cohen IS, Dixon JE, McKinnon D (1998) KCNQ2 and KCNQ3 potassium channel subunits: molecular correlates of the M-channel. Science 282:1890-1893.

Wickenden AD, Yu W, Zou A, Jegla T, Wagoner PK (2000) Retigabine, a novel anti-convulsant, enhances activation of KCNQ2/Q3 potassium channels. Mol Pharmacol 58:591-600.

Yue C, Yaari Y (2004) KCNQ/M channels control spike afterdepolarization and burst generation in hippocampal neurons. J Neurosci 24:46144624.

Yus-Najera E, Munoz A, Salvador N, Jensen BS, Rasmussen HB, Defelipe J, Villarroel A (2003) Localization of KCNQ5 in the normal and epileptic human temporal neocortex and hippocampal formation. Neuroscience 120:353-364.

Zhang L, McBain CJ (1995a) Potassium conductances underlying repolarization and after-hyperpolarization in rat CA1 hippocampal interneurones. J Physiol (Lond) 488:661-672.

Zhang L, McBain CJ (1995b) Voltage-gated potassium currents in stratum oriens-alveus inhibitory neurones of the rat CA1 hippocampus. J Physiol (Lond) 488:647-660. 